\title{
Assessment of Aquifer Performance for Oil Drainage in the Upper Pinda Reservoir of the Mibale Field
}

\author{
Ondontshia Nkoyi Jean ${ }^{1,}$, , Deko Oyema Bruno ${ }^{1}$, Wetshondo Osomba Dominique², \\ Lokata Ediho Patrick ${ }^{1}$, Kangiama Lwangi Richard ${ }^{3}$, Katambwa Madika Cedrick ${ }^{4}$, \\ Munene Asidi Djonive ${ }^{1}$, Mbudi Diambu Shams ${ }^{1}$ \\ ${ }^{1}$ Exploration and Production Department, Faculty of Oil, Gas and Renewable Energies, University of Kinshasa, Kinshasa, Congo Democratic \\ Republic \\ ${ }^{2}$ Geoscience Department, Faculty of Sciences, University of Kinshasa, Kinshasa, Congo Democratic Republic \\ ${ }^{3}$ Basic sciences Department, Faculty of Oil, Gas and Renewable Energies, University of Kinshasa, Kinshasa, Congo Democratic Republic. \\ ${ }^{4}$ Law-Economics-Management, School of Logistics, University of Versailles Saint Quentin-en-Yvelines, Versailles, France
}

\section{Email address:}

jean.ondontshia@unikin.ac.cd (O. N. Jean), brunosdeko@gmail.com (D. O. Bruno),do_owedo@yahoo.fr (W. O. Dominique), patlok@live.com (L. E. Patrick), richard.kangiama@gmail.com (K. L. Richard), cedrickkatambwa@gmail.com (K. M. Cedrick), djonive.munene@yahoo.fr (M. A. Djonive), shamsdiambu7@gmail.com (M. D. Shams)

${ }^{*}$ Corresponding author

\section{To cite this article:}

Ondontshia Nkoyi Jean, Deko Oyema Bruno, Wetshondo Osomba Dominique, Lokata Ediho Patrick, Kangiama Lwangi Richard, Katambwa Madika Cedrick, Munene Asidi Djonive, Mbudi Diambu Shams. Assessment of Aquifer Performance for Oil Drainage in the Upper Pinda Reservoir of the Mibale Field. Petroleum Science and Engineering. Vol. 5, No. 1, 2021, pp. 13-31. doi: 10.11648/j.pse.20210501.12

Received: March 8, 2021; Accepted: March 22, 2021; Published: April 1, 2021

\begin{abstract}
The Mibale field in offsore of the DRC has been producing oil since 1976. This field is faced with the arrival of massive water and the depletion of its reservoir leading to the drop in its oil production, while the injection of water is effective for several decades. Understanding the behavior of the aquifer in this reservoir is a solution to the application of effective water flooding for oil drainage to this field. The objective pursued in this study is to evaluate the performance of the aquifer on the basis of the material balance equation, to understand its behavior in maintaining or not the pressure in this reservoir in order to identify the causes related to this depletion and the influx of water despite the application of water flooding techniques. To reach this goal, the data collection during the internship made it possible to analyze and process this data using professional software. The results show that the overall drainage index of the water drainage mechanism is $84 \%$ (due to $20 \%$ for the aquifer alone and $64 \%$ for the water flooding) and $10 \%$ of oil compressibility. (IDOI), $6 \%$ of dissolved gas segregation (IDS). Reserves in this reservoir are estimated at 4.5 million barrels. The aquifer is inactive, semi-radial linear with a constant (U) estimated at $595.5 \mathrm{barrels}$ per psi (bbl / psi) and an initial volume (WI) of 347.1 million barrels (Mbbl). Cumulative contributions from this aquifer are estimated at 173,868,933 barrels for the last 42 years of operation. This aquifer alone has no influence on the inflow of water and the maintenance of pressure, but its influence increases with water from injection wells. In conclusion, this inactive aquifer is located in the carbonate Karst of Upper Pinda to the north of the deposit. Being inactive, this aquifer is not at the origin of breakthrough or coning water acting in this field. It is likely that this phenomenon is amplified by water flooding. Which allows us to classify water flooding technology among aquifer drainage mechanisms; since this significantly activates the behavior of the aquifer and has the same effects as the aquifer.
\end{abstract}

Keywords: Assessment, Aquifer Performance, Oil Drainage, Upper Pinda Reservoir, Mibale Field

\section{Introduction}

In a quest to increase productivity of many of the fields' wells or enhance the recovery of the proven hydrocarbons in place within the Lower Congo coastal oil district of the DRC, this study focusses on the upper Pinda reservoir, its recovery and performance.

The upper PINDA is an oil reservoir of the MIBALE hydrocarbon field, located in the region of Banana/ Moanda in the DRC offshore (See Figure 1). With oil commercial 
discovery announced in 1973, it came into production of in 1976 [2, 5]. The field accounts of 21 wells (producers and injectors), however it has experienced reduction in its production from year 1978 to date due to problems of water inflow, which is believed to impeding boost in oil recovery. The Mibale field is confirmed in its decline phase of production, despite its commercial oil potential which is still abundant in the reservoir. Nonetheless, the life of this field could be lengthened in exploring other mechanisms of drainages of oil in the tank and enhanced recovery.

Henceforth, this study seeks to understand the natural drainage mechanisms within the field, using field operation and production data in order to suggest better mechanism for enhance reservoir performance. As the field is produced with its reservoir depleted using active bottom water drive mechanism, we postulate that there is no acute sand control problem. In extenso, we analyse the mode of exploitation of the wells through the analysis of relevant reservoir parameters in the production history, as well the aquifer parameters to match the observed production wells respective higher water-cut (s).

Figure 1 is a map of the geographical location and its various wells in activities. It is located in the Kongo Central province, the south-western part of the DRC (red dot on the country map) and very precisely in the Lower Congo Basin offshore.

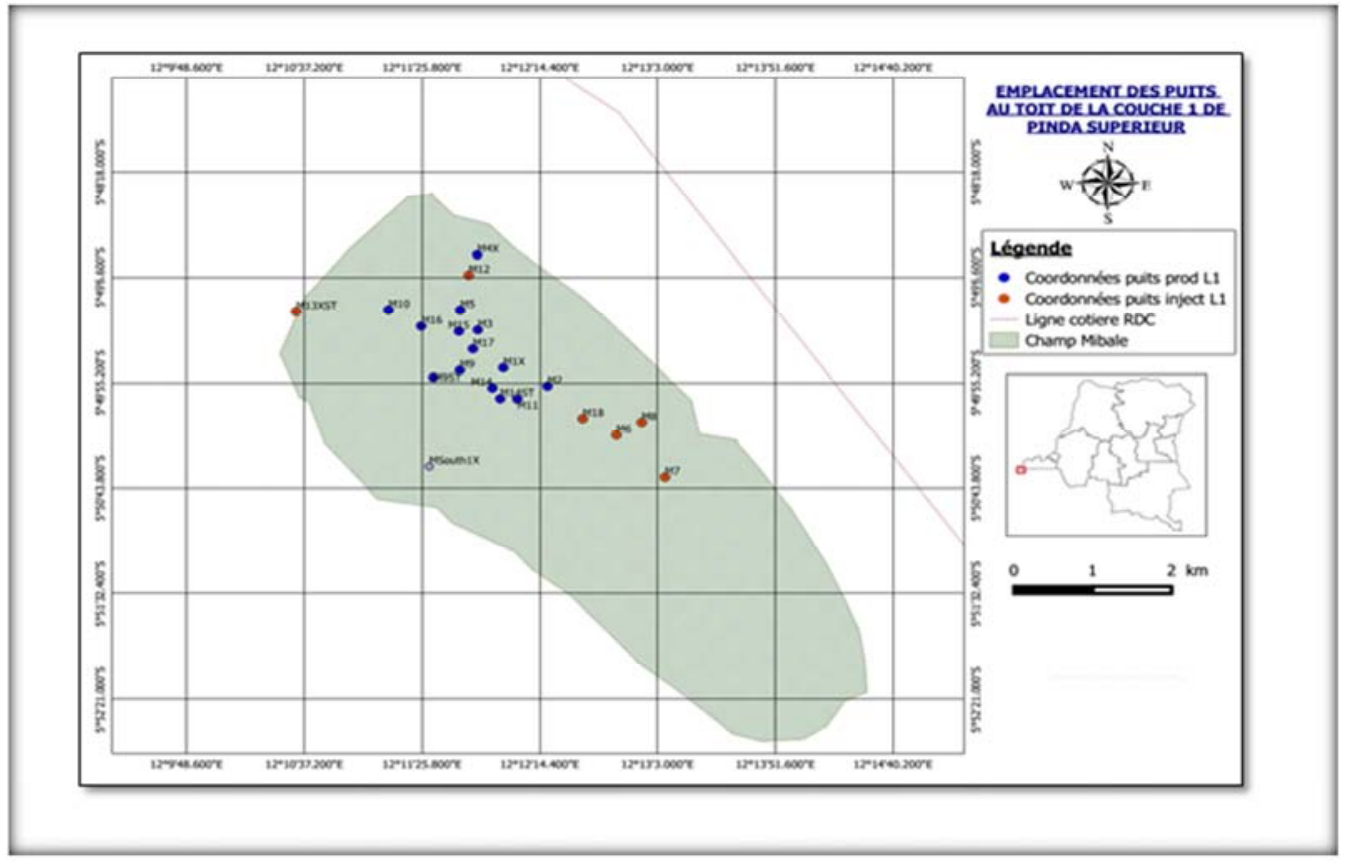

Figure 1. Location of the study area and some studied wells of the Mibale field.

In the mid-1970s Mibale field had only 8 wells, which turned it as a major producing field in 1976 with an estimated oil production of 10,000 barrels per day. As per year 2017 the wells stock stood at 21 of which 15 producers and 6 water injectors (Figure 1). By contrast, despite proven oil reserves are still significant, current field production is around 3000 barrels per day, suggesting its aquifer poor performance and poorer oil sweep with the water flooding recovery method in use. It must however be pointed out that injectors and producers can in some cases be closed temporarily if maintenance and work-over operations occur. Henceforth, Figure 1 is only a snapshot in time of the filed base management and can today (in 2021) be modified in line with field production plan.

\section{Materials and Methods}

\subsection{Methods}

Water influx into reservoirs (oil and gas) can be estimated via several mathematical approaches, known as models, as they proceed to simulate changes in pressure within the aquifer and between the aquifer and reservoir. The main approaches in use are related with the type of flow within the reservoir/ aquifer; either steady-state or unsteady-state.

An example of a steady-state flow model is the Schilthuis aquifer model $[1,20,22]$. Steady-state models assume that the rate of water influx is directly proportional to the pressure drop between the original oil-water contact (OWC) and the external aquifer boundary. For steady-state models, the pressure at the external aquifer boundary is assumed to be constant.

However, there are three other popular aquifer models which are based on unsteady state flows.

The van Everdingen and Hurst (VEH) aquifer model is an unsteady-state model, which is based on the radial diffusivity equation. The van Everdingen-Hurst aquifer model uses superposition to calculate cumulative water influx. There is in addition a pseudosteady-state flow model called the Fetkovich aquifer model. It was developed from a combination of an inflow equation and a material balance model based on the aquifer. And there is equally the 
Carter-Tracy aquifer model which is known as the approximate model, based on the van Everdingen-Hurst but considering unsteady-state model $[1,7,15]$.

For all of these approaches depend primarily on the characteristics of the aquifer and the configuration of the oil field itself; production drive mechanism and data suggest the use of the equations of HURST AND VAN EVERDINGEN for the determination of the cumulative water inflows during 42 years of exploitation of the MIBALE field. In a nutshell, we adopt this approach of unsteady state flow for the Mibale field, i.e. Edge-water drive, Bottom-water drive to assessing the problem of its water influx and performance.

\subsection{Materials}

To complete this work, several materials and tools were used. It is mainly a laptop containing the following software:

1) Geographical Information System (GIS 10.4) software at ArcGis for the development of the various maps related to the study area;

2) Inkscape software were used to determine the isobath map and some parameters of the aquifer,

3) The Petrel software version 12 also allowed us to geologically model the PINDA reservoir in order to understand the structure of the deposit,

4) The Sufer software version 11 allowed us to establish the evolution of the water and oil contact during 42 years of operation,

\section{Data and Area of Interest (Aoi)}

\subsection{Datasets}

Drilling data, well logs, and the upper PINDA reservoir fluid properties (PVT) of the 12 wells of the MIBALE field collected during the offshore Mibale field development and its production at plate-form located at MOANDA city were made available by the operating company for this study. Additional confidential production documents on the methods of exploitation of this field since 1973 were also used to validate the production mechanism, oil recovery and field reservoirs base management during the years.

\subsection{Area of Interest and Hydrocarbons}

The Mibale deposit area consists of a faulted anticlinal structure with an area of $11 \mathrm{Km}^{2}$ delimited by major faults caused by the diapiric lifting of salt of LOEME. It is part of the coastal basin of the DRC (Figure 2, below).

With a multitude of faults, the geology of the coastal basin is subdivided into two phases: before the salt commonly called ante-salt (also pre-salt) and After the salt (post-salt). The pre-salt is made of the following formations: the metamorphic basement of Mayombe, the sand of Lucula, the clays of Buccomazi (principal source rock of the Coastal Basin of the DRC), the Toca carbonate, the Chela sands generally considered a drain favorable to the migration of hydrocarbons from the BUCCOMAZI source rock to the Post-Salt Reservoirs, and the salt of LOEME $[4,5]$.

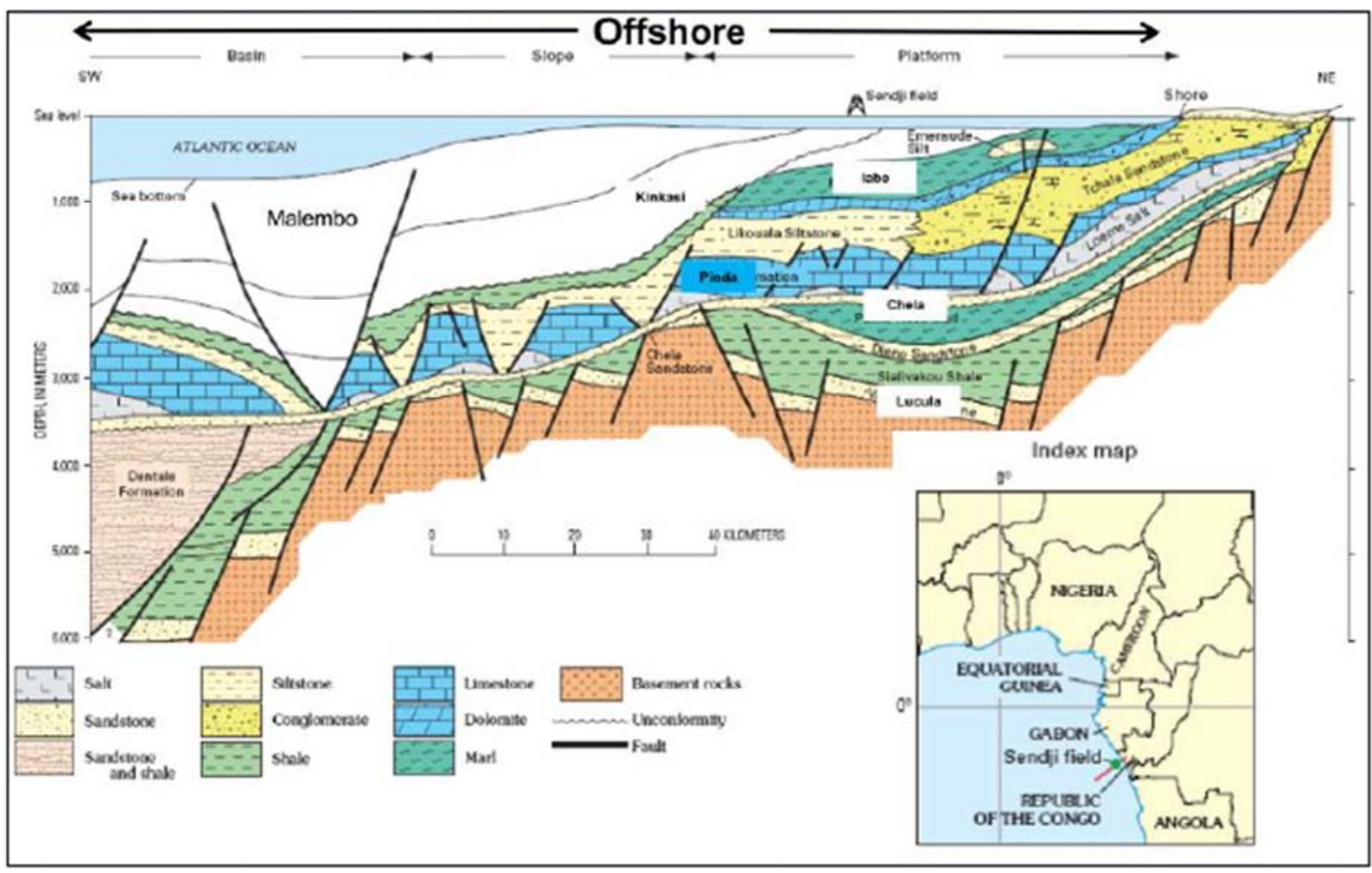

Figure 2. Geological and Structural Model of the Coastal Basin of the DRC.

Various formations of the post-salt are given in Figure 3. And the Mibale reservoir under of study is part of the PINDA formation of the post salt. 


\begin{tabular}{|c|c|c|c|c|}
\hline Period & Stage & Formation & Lithology & Lithodescription \\
\hline \multirow{3}{*}{ Tertiary } & Neogene & Malembo & 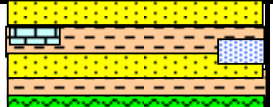 & $\begin{array}{l}\text { Uncosolidated Sand, claystone, minor carbonate and } \\
\text { carbonated sandstone }\end{array}$ \\
\hline & \multirow[t]{2}{*}{ Paleogene } & Landana & +1 & Marl, limestone, sand and claystone \\
\hline & & \multirow{2}{*}{ labe } & 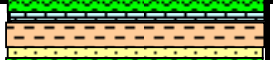 & \multirow{2}{*}{$\begin{array}{l}\text { Marl, minor limestone. Siltstone in the lower section } \\
\text { with some marl grading to limestone }\end{array}$} \\
\hline \multirow{4}{*}{ Cretaceous } & Senonian & & & \\
\hline & Turonian & Liawenda & $\ldots$ & Siltstone, Marl and minor limestone \\
\hline & Cenomanian & Kinkasi & P & Siltstone, limestone and claystone \\
\hline & Albian & Pinda & 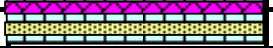 & Limestone, dolomite and sandstone \\
\hline
\end{tabular}

Figure 3. Lithostratigraphic column of post-saliferous geological formations which include the PINDA formation [12].

\subsection{Mibale Field Depositional Systems and Wells}

Mibale Upper Pinda formation is a complex structural stratified multi layered system deposited during the Albian stage of the Cretaceous period and is overlain by the Cenomanian shale member of the Iabe formation. As shown on Figure 3 above. The geological model of the reservoir adopts four basic stratigraphic zones that classify the Pinda formation:

Zone 1: the transitional interval between the shalyCenomanian (at the base of the Iabe formation that acts as the reservoir seal) and the limy Upper Pinda.

1) Zone 2: a slightly sandy, but mostly open-platform limestone.

2) Zone 3: the replaced open-platform vuggy dolomite.
3) Zone 4: supratidal to nearshore marine cyclic carbonate-clastic interbedded dolomites, dolomitic sandstones, and dolomitic shales.

For this study, indicated reservoir zones 2 through 4 which is also known as the Upper Pinda - have been subdivided into seven geologic layers (Figure 4). The seven layers thicknesses are too variable. Some of these layers are loaf, while the others have very considerable thicknesses, and the majority of them discord (angular discrepancy) towards the Northeast of the deposit. As portrayed, all units thin towards the northwest onto the Mibale field paleo-depositional high, located in the Mibale 10 area. For instance, layers 3 and 4 are also truncated to the northwest beneath the layer 2 unconformity (Figure 4).

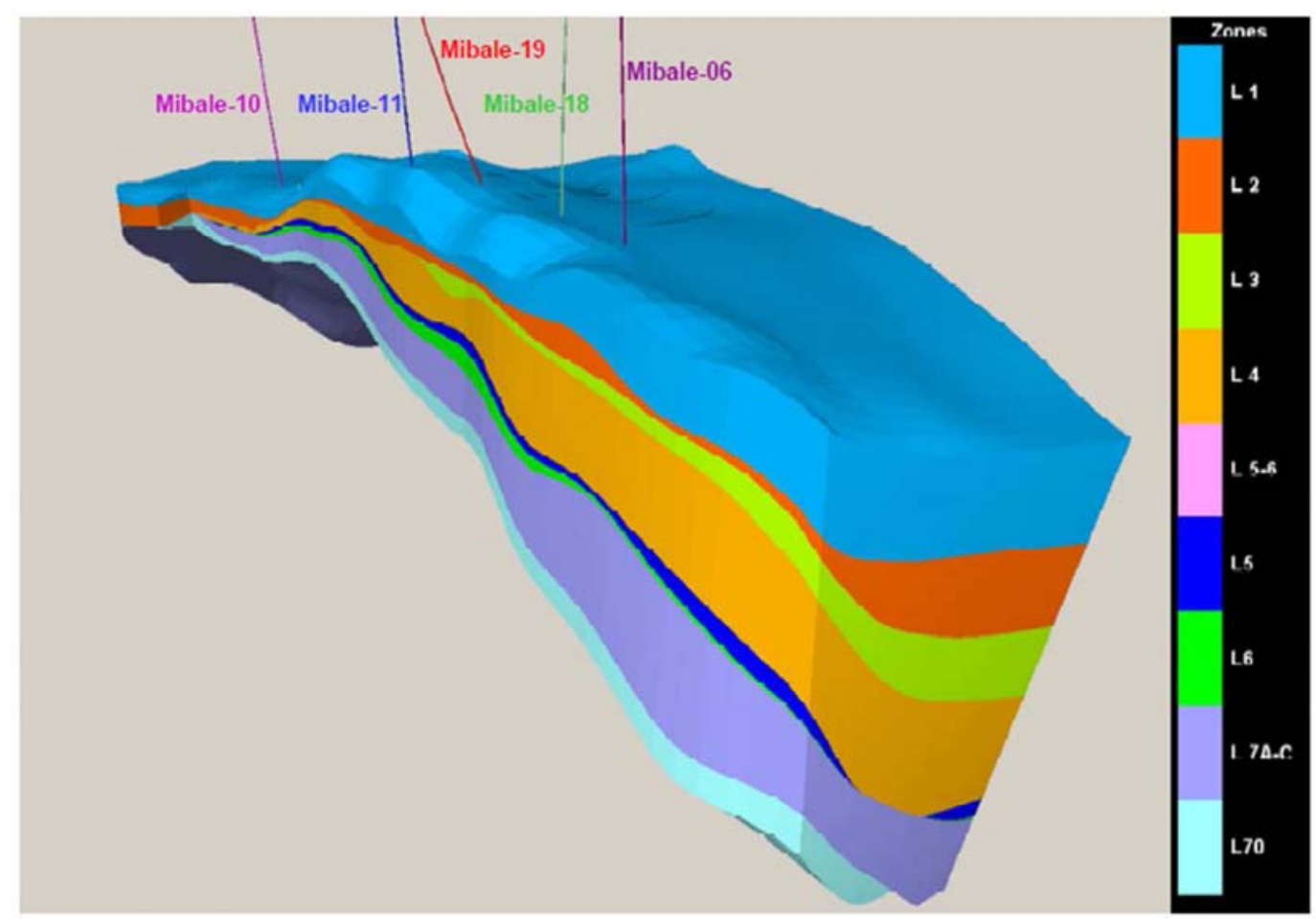

Figure 4. Mibale 3D Structure, Zonation-layers from zones 2 through 4, also showing some wells penetrations.

In addition, for a better visualisation of the horizons penetrations Figure 5 portrays a vertical cross-section some wells locations and respective trajectories (projections) within the field. 


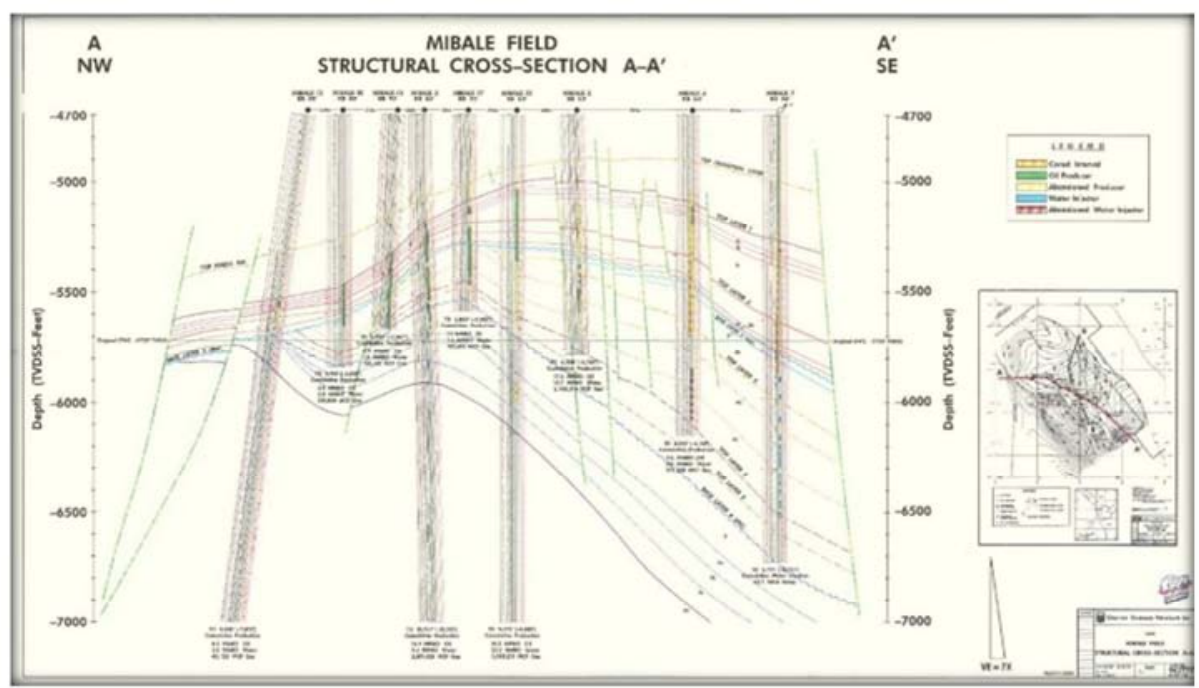

Figure 5. Mibale Field Cross Section (NW-SE) with some current and past wells.

\section{Results}

\subsection{Petrophysical Characterization of the Upper Pinda Reservoir of the Mibale Field}

Based on formation evaluation and log data analysis, the Pinda formation reservoir is modelled an heterogeneous multilayer tank as described in Figure 4. As such, it only returns variable petro-physical properties (porosity, permeability,...) which impact the flow of fluids towards producing wells.

\subsubsection{Flow vs. Facies}

The Mibale field reservoir is composed of three dominant facies (See Figure 3):

1) the dolomitic facies of good quality and especially in terms of its significant saturation of oil. This facies is met in Upper Pinda 3,

2) the calcareous facies, the worst because of their high water saturation, is found in Upper Pinda 1 and Upper Pinda 2,

3) very minor sandstone facies in the reservoir.

These three facies dominate and subdivide the reservoir into 5 layers $[2,4,5]$ some of which are not encountered in other wells following the phenomenon of dolomitization. For instance, in some wells like MIBALE 2, 3, 6, 7, 8, it is observed an absence of the predominant layer 5 in limestone facies, which is very saturated with water (See also Figures 4 and 5).

Based on the layered model of Mibale Field facies and zonation, a corresponding Net-to-Gross map is presented in Figure 6 below. Meanwhile, some characterization and variation of petrophysical parameters of the upper PINDA are given in Figure 7.

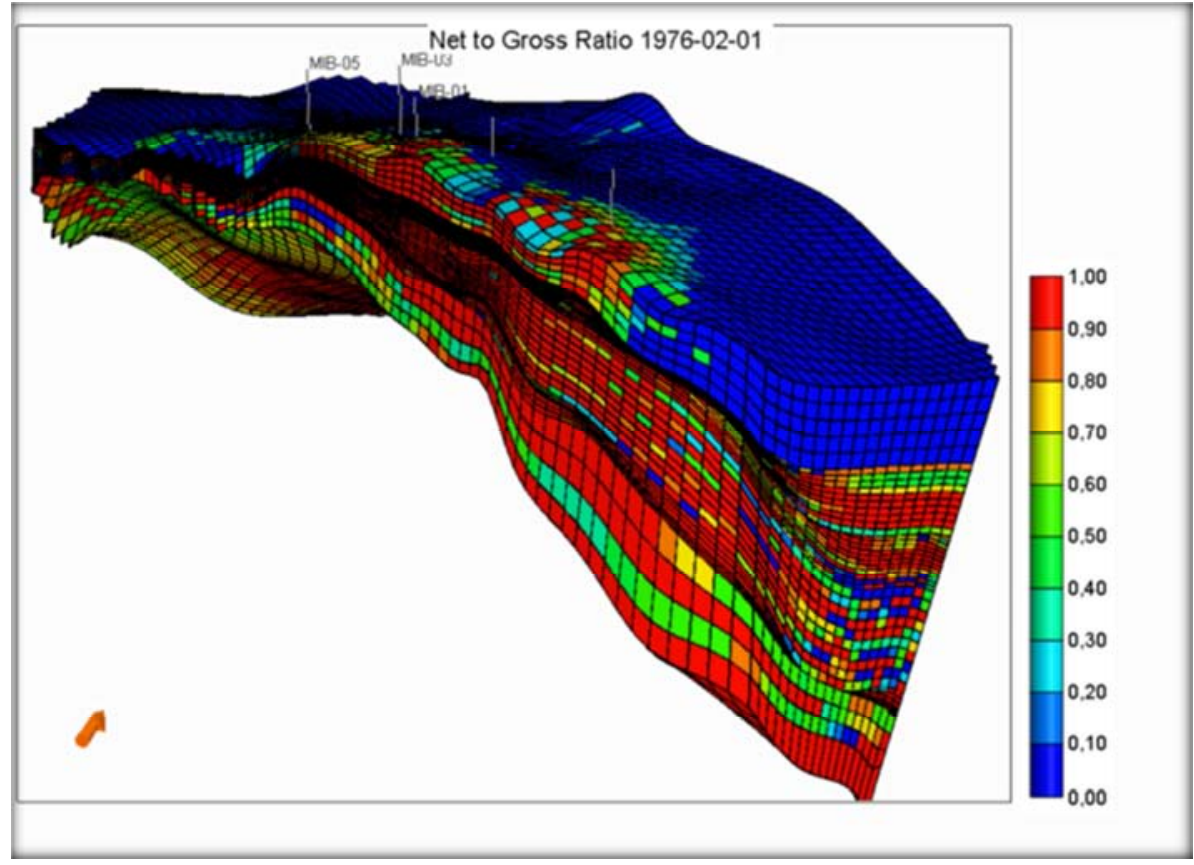

Figure 6. Mibale deposit 3D geological model and corresponding $N$ : G. 

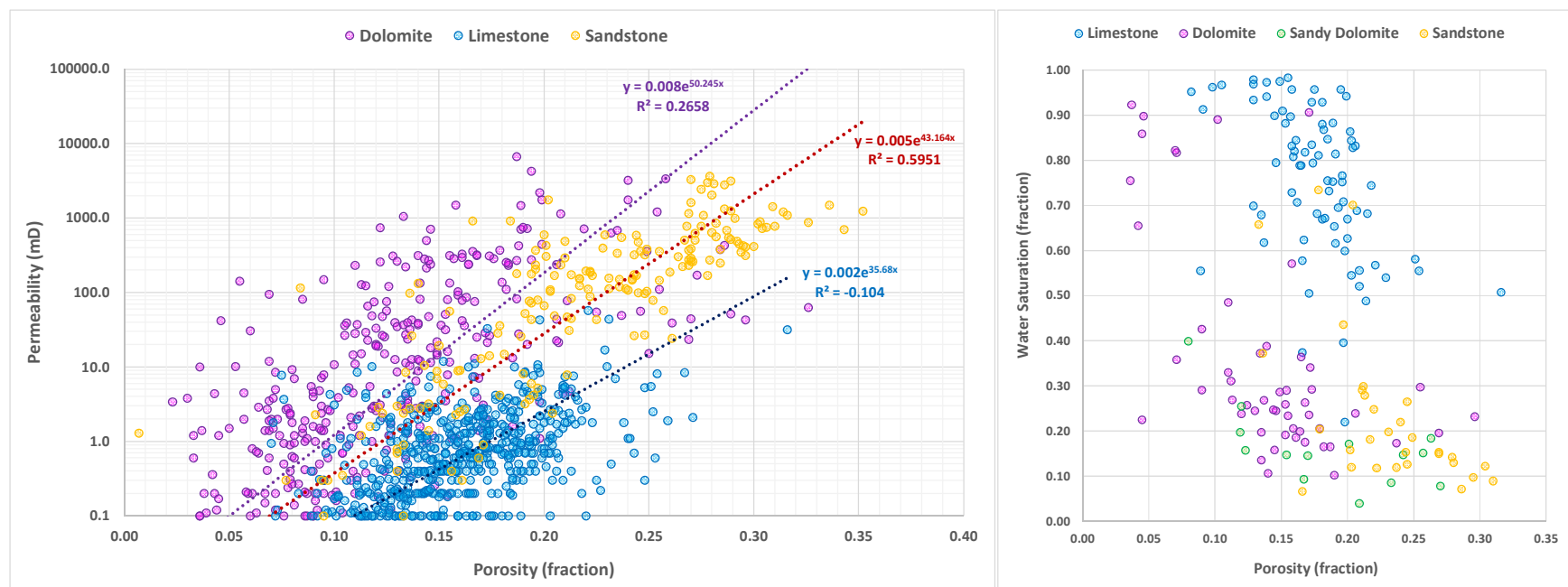

Figure 7. Characterization and variation of petrophysical parameters of the upper PINDA reservoir.

\subsubsection{Flow vs. Porosity and Permeability}

Figure 8 is contour map based on eight wells of the field at reservoir depths. It portrays the spatial distribution of porosity in those wells and translates an average reservoir porosity of about $15 \%$, which is deemed to be a good porosity. Note the porosity is variable from one area to another and it varies especially with depth $[4,5,13]$.

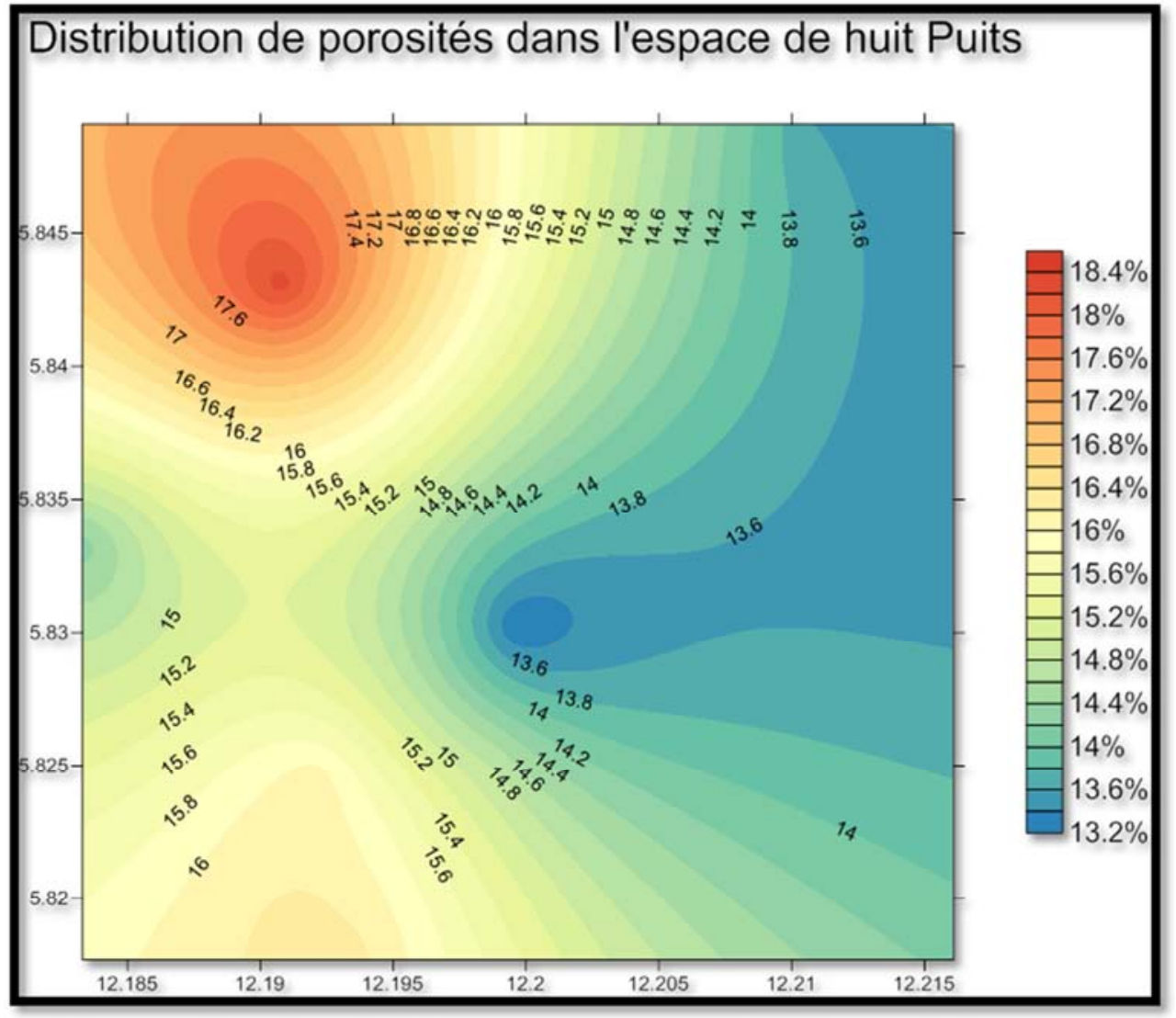

Figure 8. Spatial distribution of porosity in some wells of the Mibale field.

\subsubsection{Field Oil Water Contact}

Another important petrophysical property or data impacted by production and water drive mechanism is the field OWC, hence water breakthrough in producing wells. For the purpose of the study, we have provided a map of isobaths of field of MIBALE Field (Figure 9). 


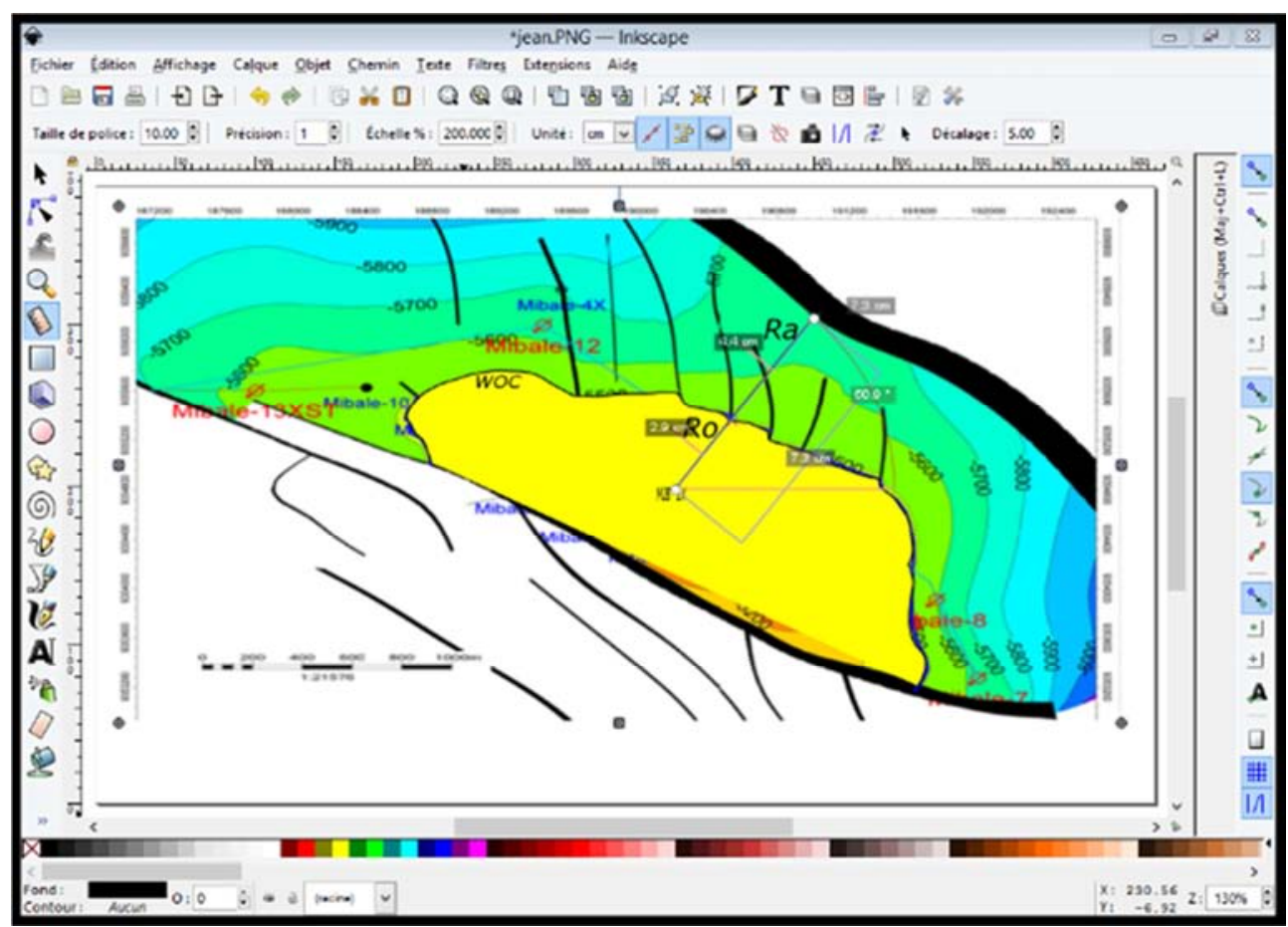

Figure 9. Isobaths map of Mibale field with some wells and current water oil contact.

\subsection{Reservoir Pressure During Production of the Deposit}

The Upper Pinda reservoir pressure evolution over the years of production (1976 to date) is captured in data plotted in Figure 10 below. The data set is made of various well tests performed at different times and within the five different producing reservoir layers, namely: Upper Pinda 1 (UP-1), Upper Pinda 2 (UP-2), Upper Pinda 3 (UP-3), Upper Pinda 4 (UP-4) and Upper Transitional Upper Pinda (UP-Trans).

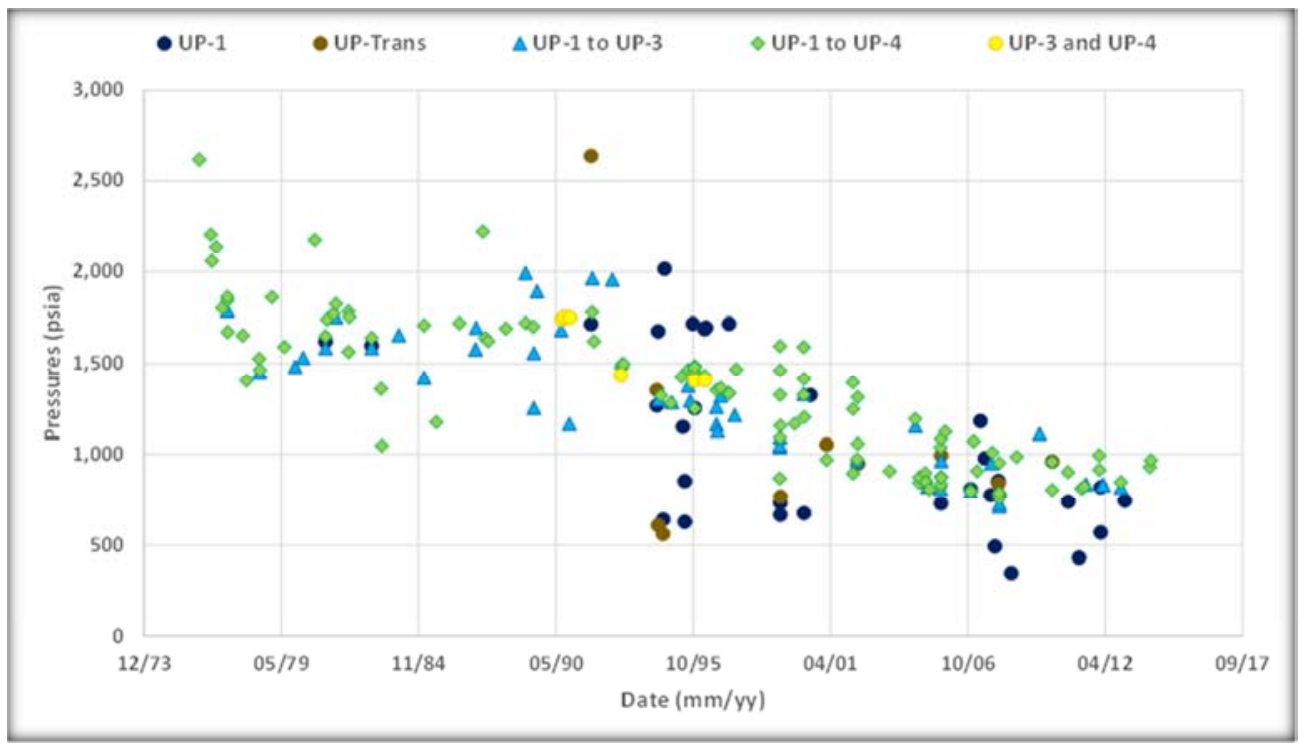

Figure 10. Point cloud illustrating the pressure evolution in each reservoir layer of the MIBALE field.

At the end of this figure which plots the pressure test data carried out in the different horizons of the Upper Pinda reservoir, we can see that each layer had its own pressure. The different facies of the Upper Pinda reservoir being communicating, the shape of the pressure evolution with the production is similar in all the lithofacies of the reservoir.

The Reserves of the MIBALE oil field were (re) evaluated by the company in 2015. The accumulations in place under standard conditions were as follows. 
Table 1. In place quantities and their PVT properties [Perenco Rep DRC, 2007].

\begin{tabular}{lllll}
\hline STOIIP in MMSTB & Np in MMSTB & Boi in RB/STB & Bgi in RB/SCF & G in MSCF \\
\hline 393 & 123 & 1.13 & 0.002 & 4000 \\
\hline
\end{tabular}

The cap gas factor is evaluated by the following formula:

$$
\begin{aligned}
m & =\frac{G B_{g i}}{N B_{o i}} \\
\text { now can } m & =\frac{4000 * 0,002}{393 * 1,13}=0,01
\end{aligned}
$$

The interpretation of this value is based on the following arguments according to other reservoir engineering researchers $[6,18]$ :

1) When $m=10$, the deposit behaves like a deposit at Water

Drive. The pressure is maintained. The GOR is constant, the gas cap is so important that it manages to maintain $\mathrm{P}$ and replace the oil produced.

2) For $m=1$, there is a partial pressure maintenance, the gas can neither maintain pressure nor replace all the oil produced.

3) For $m=0.1$, the deposit behaves like a dissolved gas deposit. No pressure maintenance and there is a GOR trigger.

In the case of the species, the field of the Mibale field was naturally characterized by a segregation mechanism due to dissolved gas. It did not have a gas cap initially (absence of Gas Oil Contact: GOC).

A deposit whose natural drainage mechanism is of the segregation (dissolved gas) type is not good at injecting water during natural depletion. The consequence of injecting water into this type of deposit is that the oil will be produced with a significant amount of gas, while another quantity of the gas will escape to form a gas cap during the operation of the deposit. This will consequently lead to an increase in the viscosity of the oil, leading to the low mobility of the latter.

The oil recovery factor, $R$, at pressures above bubble point is given by:

$$
R=\frac{N p}{N}
$$

We can use the equation (2) to calculate the recovery factor using data from table 1 . We can say, the recovery factor is:

$$
R=\frac{123000000}{393000000}=0,3129 \times 100=31,29 \%
$$

This recovery factor shows that we have not yet reached the production of even half of the oil in place (OOIP).

\subsection{Water Inflow in the Mibale Field}

\subsubsection{Hurst and Van Everdingen Equation}

Water inflows over time are evaluated in this paper by using the following HURST and VAN EVERDINGEN equation [1, $3,7,11,18]$. These influxes of water infiltrants depend on the constant of the aquifer $(\mathrm{U})$ and the pressure drop $(\Delta \mathrm{P})$ in the reservoir as a function of the exploitation time of the deposit.

$$
\begin{array}{r}
W_{e}(T)=U\left[\Delta P_{0} W_{D}\left(T_{D}\right)+\Delta P_{1} W_{D}\left(T_{D}-t_{D 1}\right)+\right. \\
\Delta P_{2} W_{D}\left(T_{D}-t_{D 2}\right)+\Delta P_{3} W_{e}\left(T_{D}-t D_{3}\right)+\cdots \\
\left.\cdots \cdots \cdots \Delta P_{j} W_{D}\left(T_{D}-t_{D j}\right)+\cdots \Delta P_{n-1} W_{D}\left(T_{D}-t_{D n-1}\right)\right]
\end{array}
$$

This equation is nothing other than the equation below in the simplified sense:

$$
W_{e}(T)=U \sum_{J=0}^{n-1} \Delta P_{j} W_{D}\left(T_{D}-T_{D J}\right)
$$

Where $U=2 \pi f \emptyset h \bar{c} r_{0}^{2}$ isnothing other than the constant of the aquifer in cc / atm, but as we work with the units of the field, then this parameter $(\mathrm{U})$ becomes:

$$
U=1,119 f \emptyset h \bar{c} r_{0}^{2}
$$

in $\mathrm{bbl} / \mathrm{psi}[10,15]$

On this paper $\mathrm{n}=42$ years, which practically corresponds to 2018, but we will limit ourselves to assessing these water inflows in 2017; since $n-1=41$ years.

hmed Tarek, 2010 shows that, the initial water volume of the aquifer can be evaluated by the following formula:

$$
W_{i}=\left[\frac{\pi\left(r_{e}^{2}-r_{0}^{2}\right) h \varnothing}{5,615}\right]
$$

At least in this article, we wanted to expand equation (4) of the aquifer constant and propose this reasoning so that at future publications we can correct these equations.

$$
t_{D}=C \times \frac{k * t}{\emptyset \mu \bar{C} r_{0}^{2}} .
$$

With $\mathrm{C}=0.000264$ if the time $(\mathrm{t})$ is in hour,

$\mathrm{C}=0.00634$ if the time $(\mathrm{t})$ is in days

$\mathrm{C}=2.309$ if the time (t) is in year. This is the case in this scientific article.

$$
W_{D(\max )}=\frac{1}{2}\left(r_{e D}^{2}-1\right) .
$$

For a radial aquifer,

$$
\mathrm{W}_{\mathrm{D}(\max )}=1
$$

for a linear aquifer Knowing that

$$
r_{e D}=\frac{r_{e}}{r_{0}}
$$

$[6,14]$.

The permeability $(K)$, the porosity $(\Phi)$ and the compressibility of the water and of the formation $(\mathrm{Cw}, \mathrm{f})$ of the PINDA reservoir of the Mibale field were studied and characterized their values are presented in Table 2 . The radius of the reservoir $\left(\mathrm{r}_{0}\right)$ and that of the aquifer (re) were found using Inkscape software after design and projection of the isobath map of the roof (Figure 9). The thickness of the aquifer is known from the logging and drilling data by positioning the Water oil Contact in all the wells in the field 
as shown in Figures 5 and 9. These different parameters are then presented in Table 2.

Table 2. Reservoir and aquifer characteristics (data from the deposit, drilling, logging \& our Upper PINDA reservoir disign).

\begin{tabular}{lllllllllll}
\hline $\mathbf{K}(\mathbf{m D})$ & $\boldsymbol{\Phi}(\mathbf{\%})$ & $\boldsymbol{\mu}(\mathbf{c p})$ & $\mathbf{C w ~} \mathbf{~ p s i}^{-1}$ & $\mathbf{C f}$ in $\mathbf{~ p s i}^{-1}$ & $\boldsymbol{r}_{\mathbf{0}}$ in ft & $\boldsymbol{r}_{e}$ in $\boldsymbol{f t}$ & $\boldsymbol{r}_{\boldsymbol{e D}}$ & $\mathbf{h}$ in ft & $\boldsymbol{f}$ & $\mathrm{U}$ in bbl/psi \\
\hline 50 & 18 & 0.4 & $3.4710^{-6}$ & $4.510^{-6}$ & $1,902.9$ & $2,886.4$ & 1.5 & 731.78 & 0.14 & 599.78 \\
\hline
\end{tabular}

Knowing the characteristics of the deposit and some parameters of the aquifer present in this deposit, let us calculate the initial volume of water in the aquifer (Wi) and the constant of this aquifer (U) using equations 5 and 6 with the data from table 2 .

$$
\begin{gathered}
W_{i}=\left[\frac{\pi\left(r_{e}^{2}-r_{0}^{2}\right) h \emptyset}{5,615}\right]=\left[\frac{3,14\left[(2886,4)^{2}-(1902,4)^{2}\right] 731,78 * 0,18}{5,615}\right] \\
W_{i}=\left[\frac{1948967005,3604352}{5,615}\right] \\
W_{i}=347100090 \mathrm{bbl} \\
W_{i} \cong 347,1 \mathrm{MMbbl}
\end{gathered}
$$

The constancy of this aquifer is then determined by:

$$
\begin{gathered}
U=1.119 f \emptyset h \bar{c} r_{0}^{2}=1.119 * 0,14 * 0.18 * 731.78 * \\
7.9710^{-6} * 3621028.41 \\
U=595.5 \mathrm{bbl} / \mathrm{Psi}
\end{gathered}
$$

Let's calculate further the dimensionless time from the following equation:

$$
t_{D}=2.309 \times \frac{k * t}{\emptyset \mu \bar{C} r_{0}^{2}}[18,19,23] .
$$

Where

$\mathrm{t}=0,1,2,3,4,5,6,7,8 \ldots .42$ years:

$$
\begin{gathered}
t_{D 0}=2.309 \times \frac{50 * 0}{0.18 * 0.4 * 7.9710^{-6} * 3619125.76}=0 \\
t_{D 1}=2.309 \times \frac{50 * 1}{0.18 * 0.4 * 7.9710^{-6} * 3619125.76}=55.5 \\
t_{D 2}=2.309 \times \frac{50 * 2}{0.18 * 0.4 * 7.9710^{-6} * 3619125.76} \\
=111.1
\end{gathered}
$$

$$
\begin{aligned}
t_{D 3}=2.309 \times & \frac{50 * 3}{0.18 * 0.4 * 7.9710^{-6} * 3619125.76} \\
& =166.6 \\
t_{D 42}=2.309 & \times \frac{50 * 42}{0.18 * 0.4 * 7.9710^{-6} * 3619125.76} \\
& =2333.5
\end{aligned}
$$

All the dimensionless time $\left(t_{D}\right)$ results are presented in the third column of Table 3 .

Now calculate the dimensionless water inputs $\left[\mathrm{W}_{\mathrm{D}}\left(\mathrm{t}_{\mathrm{D}}\right)\right]$ as a dimensionless time function $t_{\mathrm{D}}$. For this, we use the equations set out in the fourth edition of Tarek's book, 2010; showing three conditions for calculating the dimensionless water inflows $\mathrm{W}_{\mathrm{D}}\left(\mathrm{t}_{\mathrm{D}}\right)$.

1) For $t_{D}$ inferior to 0.01 :

$$
W_{e D}=2\left(\frac{t_{D}}{3.14}\right)^{0.5}
$$

2) For $0.01<t_{D}<200$ :

$W_{e D}=\frac{1.2838 \sqrt{t_{D}}+1.19328\left(t_{D}\right)+0.269872\left(t_{D}\right)^{3 / 2}+0.00855294\left(t_{D}\right)^{2}}{1+0.616599 \sqrt{t_{D}}+0.0413008 t_{D}}$

3) For $t_{D}$ supérieur à 200 :

$$
W_{e D}=\frac{-4.29881+2.02566 t_{D}}{\ln \left(t_{D}\right)}
$$

Of these three conditions, the first is excluded from our calculations of adimensional water inflow; because we do not have lower $\mathrm{t}_{\mathrm{D}} 0.01$.

Indeed, as from 1976 to 1978 the $t_{D}$ are less than 200 , then the corresponding non-dimensional inputs are calculated:

$$
\begin{gathered}
W_{e D 0}=\frac{1.2838 \sqrt{0}+1.19328(0)+0.269872(0)^{3 / 2}+0.00855294(0)^{2}}{1+0.616599 \sqrt{0}+0.0413008 * 0}=0 \\
W_{e D 1}=\frac{1.2838 \sqrt{55.5}+1.19328(55.5)+0.269872(55.5)^{3 / 2}+0.00855294(55.5)^{2}}{1+0.616599 \sqrt{55.5}+0.0413008 * 55.5} \\
W_{e D 1}=27.09 \\
W_{e D 2}=\frac{1.2838 \sqrt{111.1}+1.19328(111.1)+0.269872(111.1)^{3 / 2}+0.00855294(111.1)^{2}}{1+0.616599 \sqrt{111.1}+0.0413008 * 111.1}= \\
W_{e D 2}=46.96 \\
W_{e D 3}=\frac{1.2838 \sqrt{166.6}+1.19328(166.6)+0.269872(166.6)^{3 / 2}+0.00855294(166.6)^{2}}{1+0.616599 \sqrt{166.6}+0.0413008 * 166.6}=
\end{gathered}
$$




$$
\begin{gathered}
W_{e D 3}=65.22 \\
W_{e D 4}=\frac{-4.29881+2.02566 * 222.2}{\ln (222.4)}=82.52 \\
W_{e D 5}=\frac{-4.29881+2.02566 * 277.8}{\ln (277.8)}=99.24 \\
W_{e D 42}=\frac{-4.29881+2.02566 * 2333.5}{\ln (2333.5)}=608.98
\end{gathered}
$$

After calculating the dimensionless water inflows from the formulas (11 and 12) established in the book by Tarek, 2010, we notice that there is no difference in results between equation (11) and (12). The proof is that if we calculate the dimensionless water inflow $(\mathrm{WeD})$ whose dimensionless time is 55.6 with the two equations, we find the same answer $(26.9$ or 27.09).

So would we want to know at what level is the difference between these two equations illustrated by Tarek and the whole publishing house of this book [22] Is there any way to properly adjust the conditions of use of these two equations? The results from these formulas are identical to the values established in the tables, which confirms the validity of these tables.

\subsubsection{Computation of Average Reservoir Pressure over Period of Operation}

After pressure data compilation and computations using Microsoft Excel, this is the representation of the average pressure of the reservoir over period of operation. Each point indicates the corresponding pressure at the given time (Figure 11).

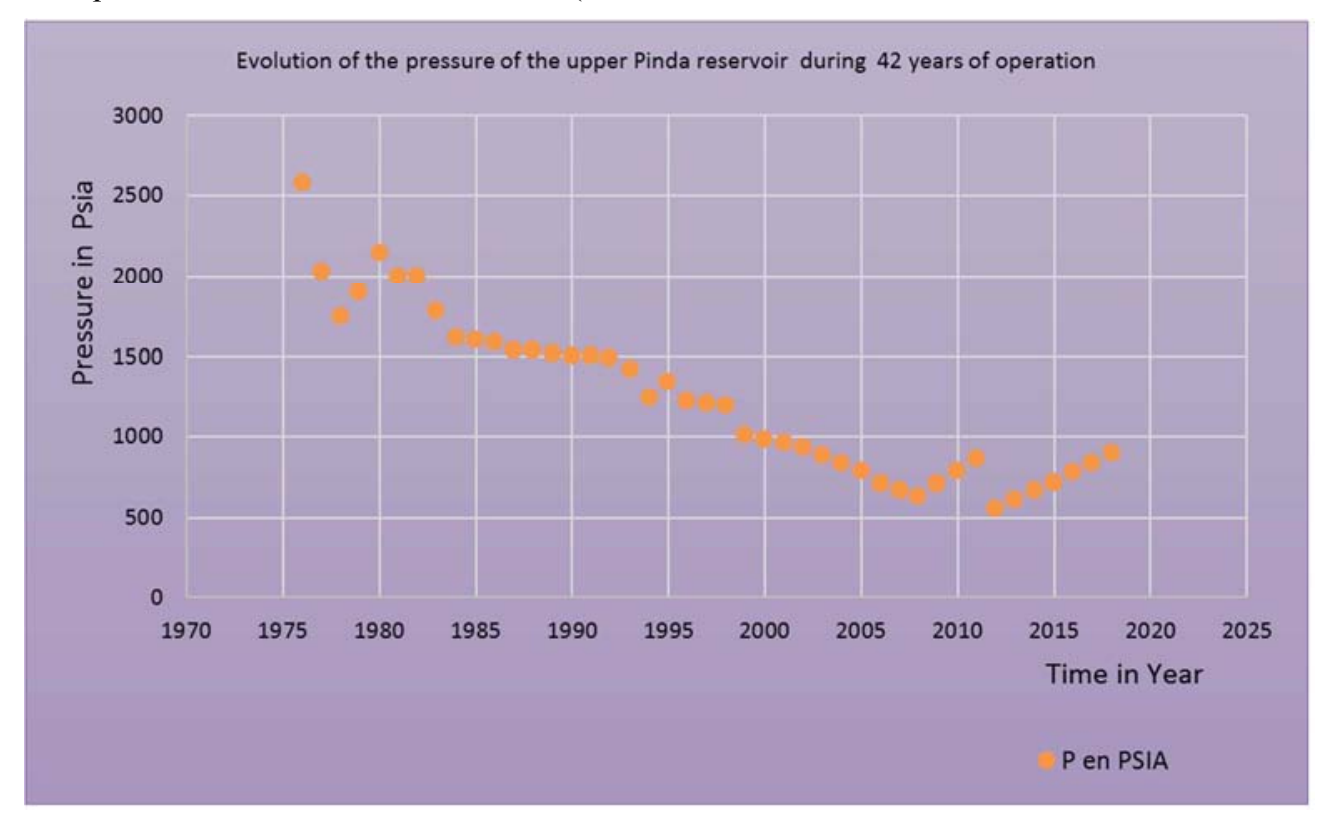

Figure 11. Clouds of points on the evolution of the pressure in the reservoir of the Mibale field.

The point clouds in the figure above reflect the evolution of the average pressure of the Upper Pinda reservoir. This development shows us how at certain periods there was a slight increase in the pressure in the tank. We can see it from 1978 until 1980, the Average tank pressure had increased from 1752 to 2145 Psi.

As we can see again between 1994 and 1995, the pressure also increased from 1249 to 1343 Psi. Arriving in 2008 until 2011, the pressure had also increased from 628 Psi to 872 Psi. This slight increase in pressure will finally be noted also over the time interval from 2012 to 2018, with an increase in pressure from 551 Psi to around 900 Psi.

All these time intervals marked by the increase in pressure have been circled in red in the figure. We can interpret these annual increases in pressure as a phenomenon which was caused by water injections into the Upper Pinda reservoir of the Mibale field and we will see below their impact on the influx.

\subsubsection{Computation of Pressure Drops as Observed over Time and Influx Water}

We know that the inflows into the deposit are a function of the pressure drop between the reservoir and the aquifer. For our case, at Edge Water Drive, leading to instability in the production of wells with generalized coning water in all Producing wells in the field, the annual pressure drops are evaluated by the method of Hurst and Van Everdingen exposed by L. DAKE.

The pressure drops occurring at times $0, \mathrm{t} 1, \mathrm{t} 2 \ldots$ etc. are then

$$
\begin{gathered}
\Delta P_{0}=\frac{P_{i}-P_{1}}{2} \\
\Delta P_{1}=\frac{P_{i}-P_{2}}{2} \\
\Delta P_{2}=\frac{P_{1}-P_{3}}{2}
\end{gathered}
$$




$$
\Delta P_{J}=\frac{P_{j-1}-P_{j+1}}{2}
$$

We can then find the pressure drops:

$$
\begin{gathered}
\Delta P_{0}=\frac{2600-2583}{2}=8.5 P s i \\
\Delta P_{1}=\frac{2600-2030}{2}=285 P s i
\end{gathered}
$$

$$
\begin{aligned}
& \Delta P_{2}=\frac{2583-1752}{2}=415.5 P s i \\
& \Delta P_{42}=\frac{784-900}{2}=-58.5 P s i
\end{aligned}
$$

\begin{tabular}{|c|c|c|c|}
\hline n (42) & Time (Years) & Pressure (Psi) & $\Delta p P s i$ \\
\hline 0 & 0 & 2600 & 8,5 \\
\hline 1 & 1976 & 2583 & 285 \\
\hline 2 & 1977 & 2030 & 415,5 \\
\hline 3 & 1978 & 1752 & 64,5 \\
\hline 4 & 1979 & 1901 & $-196,5$ \\
\hline 5 & 1980 & 2145 & -50 \\
\hline 6 & 1981 & 2001 & 73,5 \\
\hline 7 & 1982 & 1998 & 108 \\
\hline 8 & 1983 & 1785 & 188,5 \\
\hline 9 & 1984 & 1621 & 92,5 \\
\hline 10 & 1985 & 1600 & 15,5 \\
\hline 11 & 1986 & 1590 & 27,5 \\
\hline 12 & 1987 & 1545 & 25,5 \\
\hline 13 & 1988 & 1539 & 10,5 \\
\hline 14 & 1989 & 1524 & 15,5 \\
\hline 15 & 1990 & 1508 & 12 \\
\hline 16 & 1991 & 1500 & 5,5 \\
\hline 17 & 1992 & 1497 & 38,5 \\
\hline 18 & 1993 & 1423 & 124 \\
\hline 19 & 1994 & 1249 & 40 \\
\hline 20 & 1995 & 1343 & 9 \\
\hline 21 & 1996 & 1231 & 66 \\
\hline 22 & 1997 & 1211 & 15 \\
\hline 23 & 1998 & 1201 & 100 \\
\hline 24 & 1999 & 1011 & 106 \\
\hline 25 & 2000 & 989 & 20,5 \\
\hline 26 & 2001 & 970 & 29,5 \\
\hline 27 & 2002 & 930 & 40 \\
\hline 28 & 2003 & 890 & 44 \\
\hline 29 & 2004 & 842 & 48 \\
\hline 30 & 2005 & 794 & 65,5 \\
\hline 31 & 2006 & 711 & 62 \\
\hline 32 & 2007 & 670 & 41,5 \\
\hline 33 & 2008 & 628 & $-19,5$ \\
\hline 34 & 2009 & 709 & $-81,5$ \\
\hline 35 & 2010 & 791 & $-81,5$ \\
\hline 36 & 2011 & 872 & 120 \\
\hline 37 & 2012 & 551 & 131,5 \\
\hline 38 & 2013 & 609 & -58 \\
\hline 39 & 2014 & 667 & -58 \\
\hline 40 & 2015 & 725 & $-58,5$ \\
\hline 41 & 2016 & 784 & $-58,5$ \\
\hline 42 & 2017 & 842 & $-58,5$ \\
\hline 43 & 2018 & 900 & \\
\hline
\end{tabular}

The results of various pressure drop calculations are then presented in the 4 th column of Table 3.

Table 3. Presentation of pressure data from the Upper Pinda reservoir in the Mibale field.

Note. for convenience, the period (.) which means that the value is decimal has been replaced by the comma (.) in all values of the array.

The annual pressure drops were calculated using the Van Everdingen superimposition method [3, 10, 14] simplified by the equations presented above: simple difference in pressure from a previous year and the following year, divided by two or simply $\frac{P_{J-1}-P_{j+1}}{2}$. The results obtained show that certain pressure drop values are negative (less than 0 ), in Table 3. This can be interpreted as the deposit had benefited from pressure gain during these periods instead of loss in pressure.

These respective pressure benefits came from injection wells which during these periods significantly increased the quantities of injection water up to 25,000 barrels of water per day. Figure 11 indicates this increase in pressure (circled in red dotted lines) which justifies the negative pressure drops $(\Delta \mathrm{P})$ in Table 3. And since the pressure drops are in negative values, this will lead to obtaining the values of the inputs water (We) negative (less than zero) during these years.

On the other hand, the Upper Pinda reservoir is a multilayer reservoir and each of its layers has a very specific pressure and is exploited separately by the wells (Figure 5). However, certain layers are exploited by producing wells, 
others on the contrary undergo water injections and sometimes are not exploited. All these layers are connected to each other through the fault networks that affect the Upper Pinda reservoir.

The unexploited layers contain high pressures unlike those which are exploited and can under certain conditions compensate for depletion in certain layers in operation. And we think that the increase in pressure that occurred in the years may be due not only to the injection wells but also to the pressures of unexploited layers which communicate through the faults.

Table 4. Results of water entry in the Mibale deposit.

\begin{tabular}{|c|c|c|c|c|c|c|}
\hline Time (42 Years) & n (42) & $\mathbf{T}_{\mathrm{Dj}}$ & $\mathbf{U}$ in bbl/Psi & $\Delta p P s i$ & WeD & We in Mbbl/Year \\
\hline 1975 & 0 & 0 & 595,5 & 8,5 & 0 & 0 \\
\hline 1976 & 1 & 55,5 & 595,5 & 285 & 26,94 & 4572189,45 \\
\hline 1977 & 2 & 111,1 & 595,5 & 415,5 & 46,87 & 11597055,8 \\
\hline 1978 & 3 & 166,6 & 595,5 & 64,5 & 65,15 & 2502395,21 \\
\hline 1979 & 4 & 222,2 & 595,5 & $-196,5$ & 82,52 & $-9656139,69$ \\
\hline 1980 & 5 & 277,8 & 595,5 & -50 & 99,24 & -2954871 \\
\hline 1981 & 6 & 333,3 & 595,5 & 73,5 & 115,5 & 5055348,38 \\
\hline 1983 & 8 & 444,4 & 595,5 & 188,5 & 146,97 & 16497639,7 \\
\hline 1984 & 9 & 500 & 595,5 & 92,5 & 162,3 & 8940092,63 \\
\hline 1985 & 10 & 555,6 & 595,5 & 15,5 & 177,4 & 1637446,35 \\
\hline 1986 & 11 & 611,1 & 595,5 & 27,5 & 192,31 & 3149316,64 \\
\hline 1987 & 12 & 666,7 & 595,5 & 25,5 & 207,05 & 3144106,01 \\
\hline 1988 & 13 & 722,2 & 595,5 & 10,5 & 221,62 & 1385734,46 \\
\hline 1989 & 14 & 777,8 & 595,5 & 15,5 & 236,06 & 2178892,82 \\
\hline 1991 & 16 & 888,9 & 595,5 & 5,5 & 264,57 & 866532,893 \\
\hline 1992 & 17 & 944,5 & 595,5 & 38,5 & 278,66 & 6388768,16 \\
\hline 1993 & 18 & 1000,1 & 595,5 & 124 & 292,65 & 21609861,3 \\
\hline 1994 & 19 & 1055,6 & 595,5 & 40 & 306,54 & 7301782,8 \\
\hline 1995 & 20 & 1111,2 & 595,5 & 9 & 320,35 & 1716915,83 \\
\hline 1996 & 21 & 1166,7 & 595,5 & 66 & 334,07 & 13129953,2 \\
\hline 1997 & 22 & 1222,3 & 595,5 & 15 & 347,72 & 3106008,9 \\
\hline 1998 & 23 & 1277,9 & 595,5 & 100 & 361,29 & 21514819,5 \\
\hline 1999 & 24 & 1333,4 & 595,5 & 106 & 374,79 & 23657869,2 \\
\hline 2000 & 25 & 1389 & 595,5 & 20,5 & 388,24 & 4739536,86 \\
\hline 2001 & 26 & 1444,5 & 595,5 & 29,5 & 401,61 & 7055183,27 \\
\hline 2002 & 27 & 1500,1 & 595,5 & 40 & 414,93 & 9883632,6 \\
\hline 2003 & 28 & 1555,7 & 595,5 & 44 & 428,19 & 11219434,4 \\
\hline 2004 & 29 & 1611,2 & 595,5 & 48 & 441,39 & 12616691,8 \\
\hline 2005 & 30 & 1666,8 & 595,5 & 65,5 & 454,55 & 17729836,4 \\
\hline 2008 & 33 & 1833,5 & 595,5 & $-19,5$ & 493,72 & $-5733200,07$ \\
\hline 2009 & 34 & 1889 & 595,5 & $-81,5$ & 506,68 & $-24590827,1$ \\
\hline 2010 & 35 & 1944,6 & 595,5 & $-81,5$ & 519,61 & -25218362 \\
\hline 2011 & 36 & 2000,2 & 595,5 & 120 & 532,49 & 38051735,4 \\
\hline 2012 & 37 & 2055,7 & 595,5 & 131,5 & 545,33 & 42703838 \\
\hline 2013 & 38 & 2111,3 & 595,5 & -58 & 558,13 & $-19277252,1$ \\
\hline 2014 & 39 & 2166,8 & 595,5 & -58 & 570,89 & $-19717969,7$ \\
\hline 2015 & 40 & 2222,4 & 595,5 & $-58,5$ & 583,63 & $-20331772,4$ \\
\hline 2016 & 41 & 2278 & 595,5 & $-58,5$ & 596,32 & $-20773850,8$ \\
\hline 2017 & 42 & 2333,5 & 595,5 & $-58,5$ & 608,98 & -21214884 \\
\hline TOTAL We (42) & & & & & & 173868933 \\
\hline
\end{tabular}

Note. for convenience, the period (.) which means that the value is decimal has been replaced by the comma (,) in all values of the array.

Let us determine the inflows of water into our deposit through the Van Everding and Hurst equation Presented previously:

$$
\begin{gathered}
W_{e}=U \Delta P W_{e D} . \\
W_{e}(0)=595.5 \times 8.5 \times 0=0
\end{gathered}
$$$$
W_{e}(1)=595.5 \times 285 \times 26.94=4,572,189.45 \mathrm{Mbbl} / \text { Year }
$$

$$
\begin{gathered}
W_{e}(2)=595.5 \times 415.5 \times 46.87 \\
=11,597,055.8 \mathrm{Mbbl} / \text { Year } \\
W_{e}(3)=595.5 \times 64.5 \times 65.15 \\
=2,502,395.21 \mathrm{Mbbl} / \text { Year } \\
W_{e}(4)=595.5 \times(-196.5) \times 82.52 \\
=-9,656,139.69 \mathrm{Mbbl} / \text { Year }
\end{gathered}
$$




$$
\begin{gathered}
W_{e}(42)=595.5 \times(-58.5) \times 608.98 \\
=-21,214,884 \mathrm{Mbbl} / \text { Year }
\end{gathered}
$$

And then we find the cumulative water inflows during all 42 years of operation of this field by adding all the calculated annual water inflows.

$$
\begin{gathered}
W_{e}(T)=W_{e}(1)+W_{e}(2)+W_{e}(3)+W_{e}(4)+W_{e}(5)+ \\
W_{e}(6)+\cdots \cdots \cdot W_{e}
\end{gathered}
$$

We can present this equation in simplified form as follows:

$$
W_{e}(T)=U \sum_{J=0}^{n-1} \Delta P_{j} W_{D}\left(T_{D}-T_{D J}\right) .
$$

The overall result of these entries is represented by the figure below:

$$
W_{e}(T)=173868933 \frac{\mathrm{Mbbl}}{42} \text { years }
$$

Table 4 presents in its last column all the results of calculations on the influx of water into the reservoir of the Mibale field.

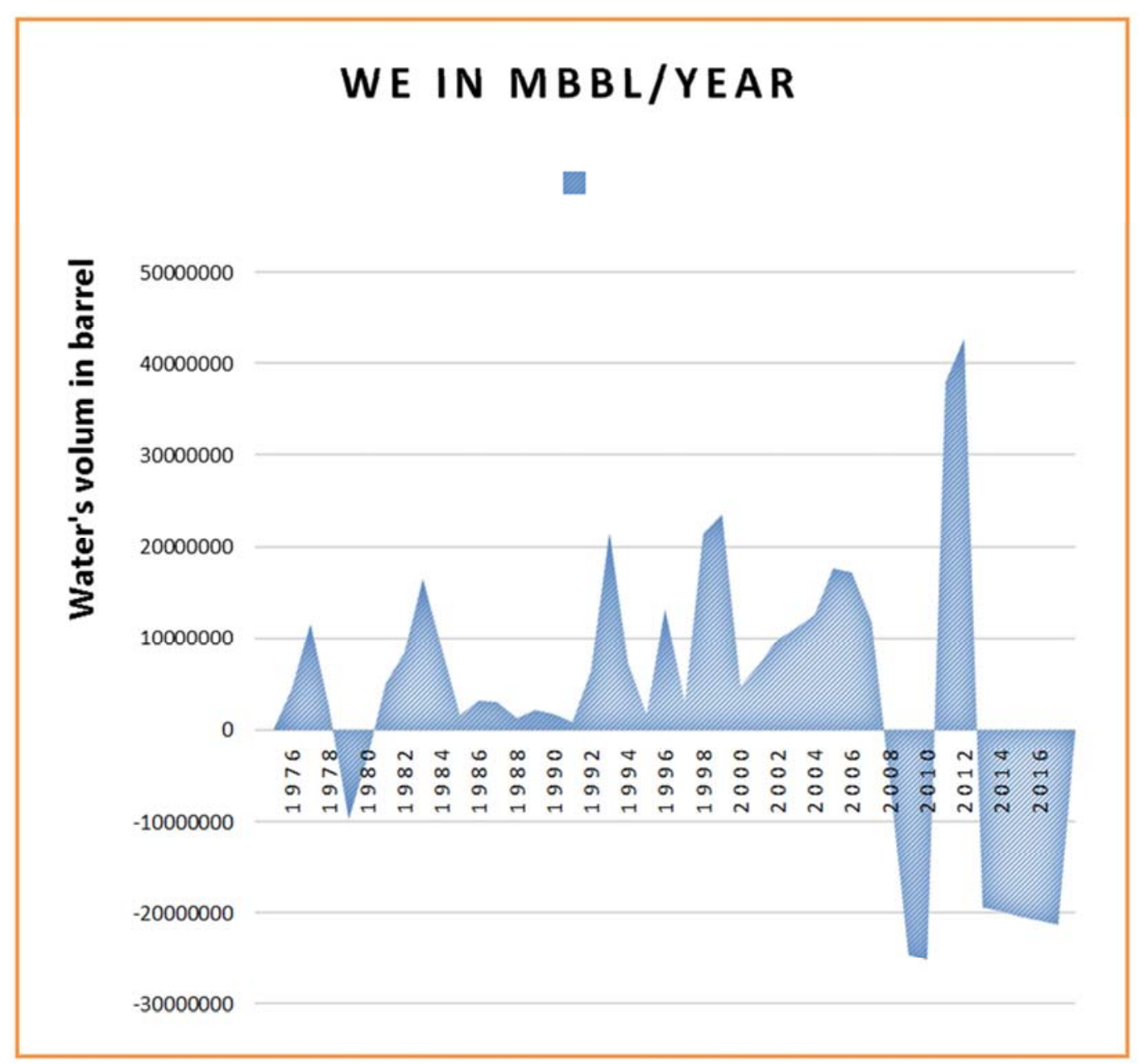

Figure 12. Presentation of periods of inactivity of the aquifer in the upper pinda reservoir of the Mibale field.

We predicted this in the previous paragraphs; the overall results clearly show that the inflows are affected by the pressure drop, and that in all years when the pressure drop values are negative, the water inflows are negative; we say that there was no influx of water at those times. The aquifer present in this field is inactive or still not supplied, exerting a low pressure in the Upper Pinda reservoir of the Mibale field.

The cumulative inflows of water during 42 years of operation of this field are calculated and are around $173,868,933$ Barrels of water supplied by the aquifer.

The latter are evaluated each year on the basis of equation (4), the results being presented in the last column of Table 4, we present below, the inactivity periods of the aquifer in the Upper Pinda Mibale field reservoir Figure 12.
From this figure we have identified three eras during which the aquifer had not exerted its effect on the oil reservoir. The first era dates from 1978 to 1980 when we see negative water inflows into the reservoir. This period corresponds to the period during which water injections had started in the Upper Pinda reservoir of the Mibale field. The second era occurred in 2008 and 2010. And the third is from 2013 until 2017.

We can interpret the periods when the water inflows are negative as years during which the aquifer did not inject water into the reservoir, in other words the years when the aquifer did not exert its effects in the reservoir (inactive aquifer). And as this periodically manifests, we say that the aquifer was not supplied regularly. 


\subsubsection{Mibale Field Oil Water Contact $(O W C)$ Variation over the Years of Production, as a Consequence of Water Influx}

The reservoir oil water contact (OWC) was penetrated at 5,720 feet true vertical depth subsea (TVDSS) by exploration well in Mibale 1X in 1976 and by all wells. Currently, the known OWC is located at depth 5,500 feet true vertical depth subsea (TVDSS). There has been a net variation of 220 feet during the production years. Considering the 42 years since the first oil, this translates into the original OWC moving up an average of 5.23 feet annually.

In this table, it is a question of showing by calculation the sudden variations by the water oil contact during the 42 years of exploitation of the Mibale field. Original Oil Water
Contact (OOWC) was found averagely in all wells in the field at a depth of 5,720 feet (figures 5 and 9). In 2017 the Current Water Oil Contact (CWOC) is at 5,500 feet. We proceed as follows:

$$
\Delta W O C_{42}=\frac{5,720-5,500}{42}=5.23 \text { feet annually }
$$

From this response, subtract from the value of the original contact water $(5,720-5.23=5,714.77)$ to find the WOC corresponding to a given period. This is what gives the results on the table above.

The results of the variation of the OWC shown in Table 5 are also modelled and presented both vertically and horizontally in Figures 13 and 14, respectively.

Table 5. Water Oil Contact (WOC) variation in the MIBALE field.

\begin{tabular}{|c|c|c|}
\hline$n^{\circ}$ & time $($ year $)=42$ years & $\Delta w o c$ in (feet) \\
\hline 1 & 1976 & 5720 \\
\hline 2 & 1977 & 5714,77 \\
\hline 3 & 1978 & 5709,54 \\
\hline 4 & 1979 & 5704,31 \\
\hline 5 & 1980 & 5699,08 \\
\hline 6 & 1981 & 5693,85 \\
\hline 7 & 1982 & 5688,62 \\
\hline 8 & 1983 & 5683,39 \\
\hline 9 & 1984 & 5678,16 \\
\hline 10 & 1985 & 5672,93 \\
\hline 11 & 1986 & 5667,7 \\
\hline 12 & 1987 & 5662,47 \\
\hline 13 & 1988 & 5657,24 \\
\hline 14 & 1989 & 5652,01 \\
\hline 15 & 1990 & 5646,78 \\
\hline 16 & 1991 & 5641,55 \\
\hline 17 & 1992 & 5636,32 \\
\hline 18 & 1993 & 5631,09 \\
\hline 19 & 1994 & 5625,86 \\
\hline 20 & 1995 & 5620,63 \\
\hline 21 & 1996 & 5615,4 \\
\hline 22 & 1997 & 5610,17 \\
\hline 23 & 1998 & 5604,94 \\
\hline 24 & 1999 & 5599,71 \\
\hline 25 & 2000 & 5594,48 \\
\hline 26 & 2001 & 5589,25 \\
\hline 27 & 2002 & 5584,02 \\
\hline 28 & 2003 & 5578,79 \\
\hline 29 & 2004 & 5573,56 \\
\hline 30 & 2005 & 5568,33 \\
\hline 31 & 2006 & 5563,1 \\
\hline 32 & 2007 & 5557,87 \\
\hline 33 & 2008 & 5552,64 \\
\hline 34 & 2009 & 5547,41 \\
\hline 35 & 2010 & 5542,18 \\
\hline 36 & 2011 & 5536,95 \\
\hline 37 & 2012 & 5531,72 \\
\hline 38 & 2013 & 5526,49 \\
\hline 39 & 2014 & 5521,26 \\
\hline 40 & 2015 & 5516,03 \\
\hline 41 & 2016 & 5510,8 \\
\hline 42 & 2017 & 5505,57 \\
\hline AOWC & 42 ans & 5500,34 \\
\hline
\end{tabular}

Note. For convenience, the period (.) which means that the value is decimal has been replaced by the comma (,) in all values of the array 


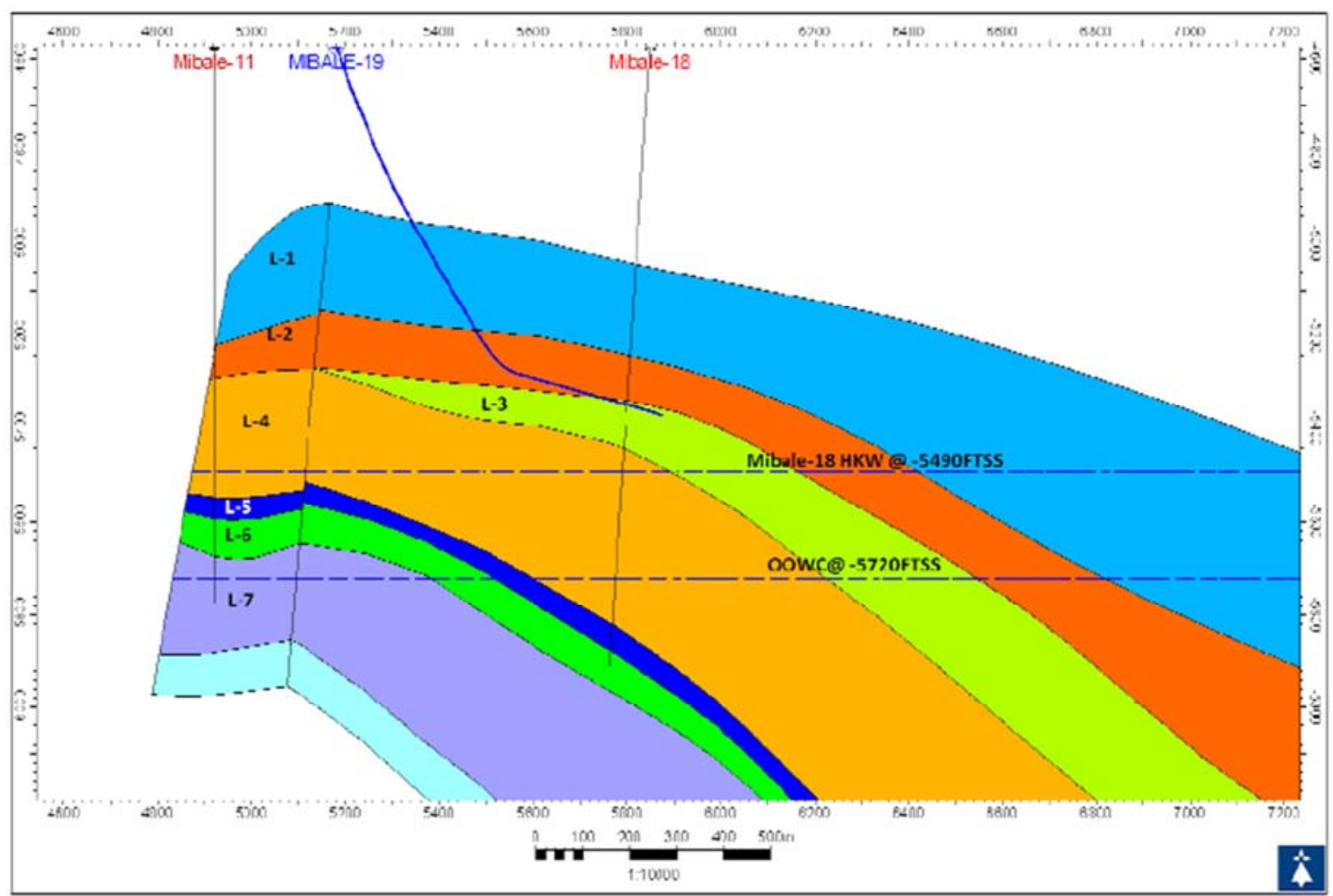

Figure 13. Modelling of the Water Oil Contact variation in the MIBALE field in vertical Plan.

Les variations de WOC pendant 42 ans (1976-2018) d'exploitation du gisement du champ MIBALE

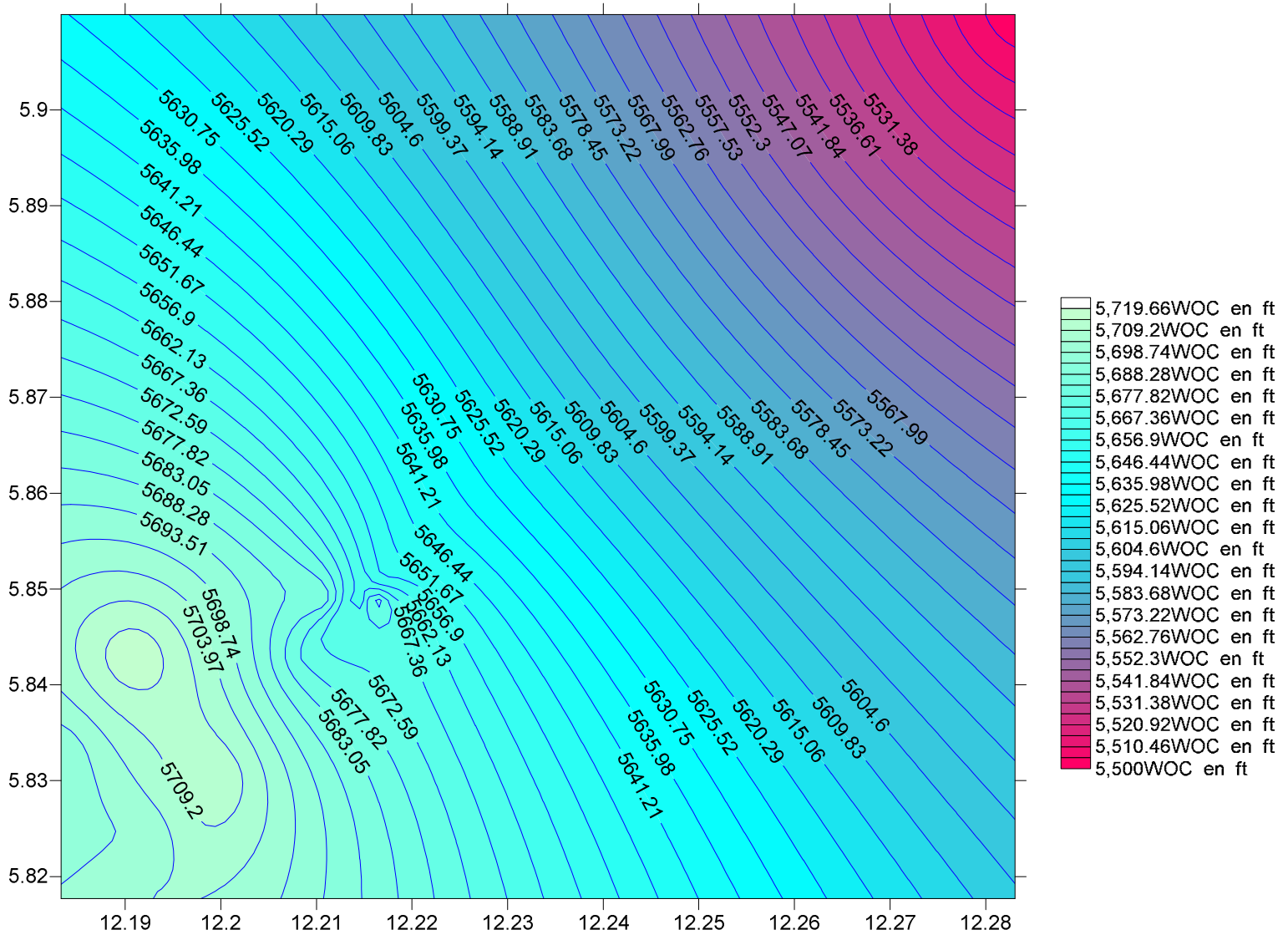

Figure 14. Modelling of the Water Oil Contact variation in the MIBALE field in Horizontal Plan. 
The Upper Pinda reservoir of the Mibale field is a multi-layered reservoir. It has, been subdivided into seven layers (L-1, L-2, L-3, L-4,...) and coloured respectively (Figure 13 above, also Figure 4). The initial or original WOC was readjusted to the depth 5720 feet and currently it is encountered at 5500 feet in the Mibale well 18.

The vertical cross section shows the position of the Mibale well 19 penetrating layer L2 in red color with its toe (Total Depth) above the OWC, allowing it to produce the oils contained in the L2 layer of the Upper Pinda reservoir. The other two wells (Mibale 11 and 18) already have their toes (Total Depth) below the actual Oil water contact. With this arrangement of the well, if their perforations are not checked, they are already drowned in the water part; which will lead to water production. Figure 14 however presents the well facing the mounted water oil contact (WOC), i.e. showing how this contact varies horizontally.

In this part, we show in an horizontal plane the variation of Water Oil Contact. Looking to the right of this figure, a scale indicartive of the color is mensionne; all the sides where we have the blue colors in other words 6 where the values of our curves of 5709.2 feet, up to the value of 5600 feet average, we are in areas where the increase in water is maximum $(100 \%)$.

This is to say that if a well has been perforated moderately at this depth, its perforation will be in the water zones and the consequence: the enormous production of water manifested on the surface by the increase of water cut. This reasoning should be properly illuminated by means of the Mibale 11 and Mibale 18 wells. Since Mibale 19 is a directional well above water contact, it will not be able to do so because it is in the oil zone.

\subsubsection{Determination of Mibale Field the Global Drainage Index}

In most books on reservoir engineering $[6,9,10,22]$ the General Material Balance equation is the sum of the indexes of drainage mechanisms linked to the petroleum reservoir. We determine the index of reservoir drainage mechanisms by water to assess the performance of the aquifer studied in this article.

The other drainage indexes will follow to calculate the overall drainage index of the field from their sum, and compare the results of these drainage indexes in order to deduce the most effective drainage mechanism in this field.

For the aquifer, the researchers $[18,22]$ have shown that the drainage index of the aquifer is evaluated by:

$$
I_{a q}=\frac{\left(W_{e}-W_{P} B_{w}\right)}{N_{P}\left[B_{t}+\left(R_{p}-R_{s i}\right) B_{g}\right]}
$$

Formula 16 assesses the performance of the aquifer alone in draining oil from the reservoir.

Knowing that

$$
B_{t}=B_{0}+\left(R_{s i}-R_{s}\right) B_{g}
$$

The oil expansion drainage index is also determined by the following formula from Tareck and the other authors:

$$
\mathrm{I}_{0 \mathrm{D}}=\frac{\mathrm{N}\left(\mathrm{B}_{\mathrm{t}}-\mathrm{B}_{\mathrm{ti}}\right)}{\mathrm{N}_{\mathrm{P}}\left[\mathrm{B}_{\mathrm{t}}+\left(\mathrm{R}_{\mathrm{p}}-\mathrm{R}_{\mathrm{si}}\right) \mathrm{B}_{\mathrm{g}}\right]}
$$

Since the Mibale field deposit does not have a gas cap, its gas is dissolved. in this case we can estimate the drainage index by segregation by the following mathematical formula:

$$
I_{S D}=\frac{N[R s i-R s) B g-\left(B_{0 i}-B_{0}\right]}{N_{P} B_{0}+N_{P}\left[\left(R_{p}-R_{s i}\right) B_{g}\right]}
$$

Reservoir engineering specialists $[8,16,21]$ show that in a gas cap and influx tank, the index of drainage by water compressibility and formation is negligible. We can then calculate the sum of all these three indexes which is equal to 1 . Either mathematically we write:

$$
\mathrm{I}_{\mathrm{WD}}+\mathrm{I}_{0 \mathrm{D}}+\mathrm{I}_{\mathrm{SD}}=100 \%
$$

$[15,17]$.

The following Upper Pinda reservoir data were used to determine this drainage index.

Table 6. The available PVT data for Oil, Gas and Water of Mibale reservoir are summarised as follow.

\begin{tabular}{lll}
\hline Mibale Upper Pinda PVT Data & & Current Reservoir Condition \\
\hline Parameters & Initial Réservoir conditions & 900 \\
\hline Pressure (Psi) & 2600 & 1336 psia \\
Bubble point & 300 & 250 \\
Rs & & 2500 SCF/STB \\
Rp & 1.13 & 1.18 \\
Bo (rb/STB) & 0.002 & 0,001 \\
Bg (RB/SCF) & 1.001 & 1.001 \\
Bw (RB/STB) & 0 & 173868933 \\
We, MMbbl & 0 & 27156000 \\
Wp, MMbbl &
\end{tabular}

$$
\begin{gathered}
\mathrm{AsB}_{\mathrm{t}}=\mathrm{B}_{0}+\left(\mathrm{R}_{\mathrm{si}}-\mathrm{R}_{\mathrm{s}}\right) \mathrm{B}_{\mathrm{g}}=1.12+(300-200) \times 0.002=1.32 \mathrm{RB} / \mathrm{STB} . \\
\mathrm{I}_{0 \mathrm{D}}=\frac{393,000,000(1.32-1.13)}{123,000,000[1.32+(2,500-300) \times 0.002]}=0.10 \approx 10 \%
\end{gathered}
$$




$$
\mathrm{I}_{\mathrm{SD}}=\frac{393,000,000[300-250) 0.002-(1.13-1.18]}{123,000,000 \times 1.18+123,000,000[(2,500-300) 0.002]}=0.057 \approx 6 \%
$$

By applying equation 20, we can derive the water drainage index.

$$
I_{W D}=1-0.16 \text { soit } 0.84 \text { Which represents } 84 \% \text {. }
$$

Compared to the other indices of the drainage mechanism acting in the Mibale field, we notice that drainage by water is more effective than others. But this index of drainage of hydrocarbons by water which is around $84 \%$ represents the injection water from the wells and that of the aquifer.

To evaluate the contribution of the aquifer alone in this $84 \%$, we will use equation 16 to determine the drainage index of the aquifer alone without the contribution of the water injection wells. This will mainly take into account the influx of water from the aquifer and the water produced in this field.

$$
\begin{gathered}
I_{a q}=\frac{(173,868,933-27,156,000 \times 1.001)}{123,000,000[1.32+(2,500-300) \times 0.002]}=0.20 \\
\approx 20 \%
\end{gathered}
$$

If we subtract in $84 \%$ of the index of drainage by water, the $20 \%$ found as the index of drainage by aquifer, and $16 \%$ found as the Oil compressibility and gas segregation Index of drainage, we realize that the injection water of the wells play a very capital role in the drainage oils in the tank of the Mibale field. Injection well water alone contributes to drainage up to $64 \%$ out of $84 \%$.

Knowing that the Material Balance equation in linear form is written as follows $[18,19,22]$ :

$$
F=N\left(E_{0}+m E_{g}+E_{f, w}\right)+W_{e}
$$

The gas cap factor being zero, the cap gas in the reservoir of the Mibale field has no effect on oil production, this results in a reduction of the previous equation to the form:

$$
F=N\left(E_{0}\right)+W_{e}
$$

Knowing that $E_{O}=B_{O}-B_{o i}=1.18-1.13=$ $0.05 \mathrm{rb} / \mathrm{STB}$

Using equation (22), allows us to draw the graph whose equation will be presented as follows [:

$$
\frac{F}{E_{0}}=N+\frac{W_{e}}{E_{0}}
$$

According to Havlena and Odeh [11, 22, 23] the parameters which constitute this equation (23) plotted on a two-axis Cartesian graph can better characterize the aquifer and allow to find the Original Oil in Place (N).

We use equation 22 can be used to calculate the volume of fluids supported in the Mibale field reservoir.

$F=393000000 \times 0.05+173868933=193,518,933$

barrels of fluids withdrawn from the Mibale field deposit from 1976 to 2017.

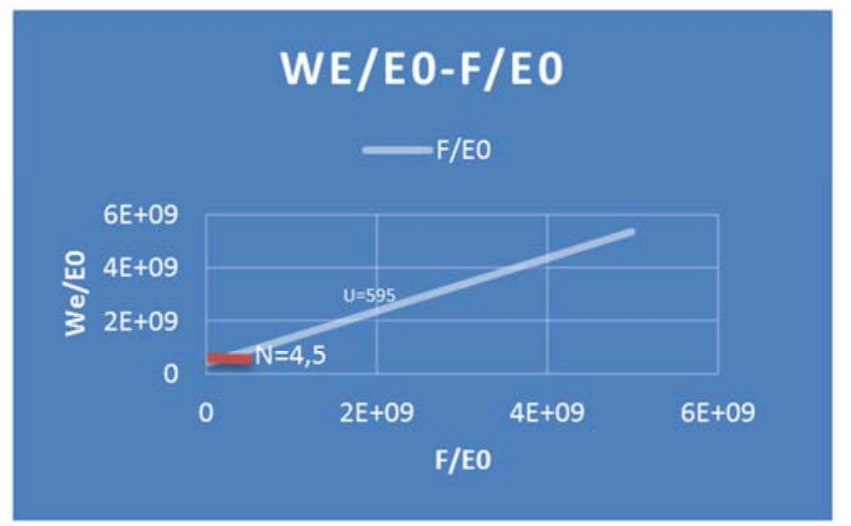

Figure 15. Calculation of $N$ in Mibale field with Alvena and Odeh Method.

\section{Discussions}

\subsection{Mibale Field: Structure, Faces and Impact in Oil Recovery}

The structure of the deposit is a faulty anticline formed after Loeme's salt tectonic. This reasoning is confirmed by the drilling data and by the work of GAFFNEY and BIMBANGA $[2,5]$. The reservoir of the deposit is composed of three types of dominant facies:

1) Dolomitic,

2) Limestone,

3) Sandstone of good porosity but very minor.

The reservoir of the Mibale field is heterogeneous, this heterogeneity of the reservoir has a great influence on the directional permeability of the reservoir.

The correlation analysis between permeability and porosity shows that the correlation coefficient is low in the three litho facies of the Upper PINDA reservoir. The low value of this correlation can justify of low permeability on the upper Pinda reservoir.

\subsection{Water Influx and Pressure Drops in the Upper Pinda Reservoir}

This reservoir was operated initially with a pressure of 2600 Psi in 1976 and today (2017) this reservoir has an average pressure of 900 Psi having experienced an average pressure drop of 1683.1 Psi. This drop in pressure was poorly maintained until 2017 thanks to the water injections that occurred in 1978 through wells: Mibale 7, Mibale 8, Mibale 13 ST, Mibale 12.

The assessment of water influx in this deposit indicates that the deposit aquiferhad a water volume of around 347,100,090 barrels. With its constancy of the aquifer (U) evaluated at the turn of 595,5 barrels per Psi, which provided a cumulative volume of water inflow (We) evaluated at 173,868,933 barrels.

Analysis of the influx of water shows that this aquifer was not active, it exerts its effects periodically and that is when there is water injection into the field. We note that the aquifer 
of the Mibale field is not naturally supplied. Its influence is controlled by water injector wells.

The evaluation of the drainage mechanism in the Mibale field shows us that the water from the injection wells remains the only mechanism that contributes to the drainage of hydrocarbons in this reservoir. They contribute to capacity building of the inactive aquifer by giving it a power to drain a total of $84 \%$ against $16 \%$ of the other drainage mechanisms: oil expansion and dissolved gas expansion.

The predominant drainage mechanism of the Upper Pinda reservoir and the use the linear Material Balance equation shows that since 1976 until today, a sustained volume (F) of fluids of 193,518,933 barrels of fluids has been achieved in the Upper Pinda reservoir of the Mibale field.

From this value we subtract the 123,000,000 Barrels of Oil Products $(\mathrm{Np})$ in the field, we find that $70,518,933$ barrels represent other fluids (water and gas) Produced for 42 years. And of these 70,518,933 barrels by subtracting 27,156,000 barrels which represent the cumulative production of water (Wp) (show table 6), we estimate gas production at 43,362,933 barrels of gas, equivalent to $155,151.49$ Million Standard Cubic Feef (Mscf) produced in the Mibale field.

\subsection{Recovery Factor}

With a recovery factor of $31.29 \%$, the cumulative production of oils has not yet reached half of the original oil in place (OOIP). This shows that 270 million barrels of oil are still present in the Upper Pinda reservoir. To be able to recover these oils and increase the recovery factors, it is important to think of new technologies for optimizing wells in operation. If not before the Expiration of the Exploitation contract in 2023, the PERENCO-Rep Company would leave significant quantities in this tank. This can be one of the motivating reasons for the company to renegotiate for the renewal of its contract which goes up to 2040 .

\section{Conclusions}

The study on the assessment of aquifer performance for oil drainage in the Upper Pinda reservoir, aimed to determine the inflows of water supplied by the aquifer to understand the role played by this aquifer in the oil recovery and possibly determine its performance.

To reach this goal, the use of the Van Everdingen and Hurst equation coupled with the Material Balance equation, borehole geological data and reservoir data collected by the operating company were processed and analyzed to constitute these manuscripts.

From this study we say that the field has a reservoir of lithological nature carbonated, characterized by three dominant facies:

1) The dolomitic facies of good quality and especially containing important hydrocarbon reserves. This facies is met in Upper Pinda 3,

2) calcareous facies, very bad due to their high saturation in water, it is found in Upper Pinda 1 and Upper 2,

3 ) The very minor sandstone facies in the reservoir has a mean porosity of 22 percent $(\%)$.

The aquifer is inactive, only allowing it to maintain the reservoir pressure. Its inflows of water calculated at the height of 173,868,933 barrels are not supplied regularly. This aquifer has a drainage index (Iaq) of drainage evaluated at $20 \%$, associated with injection water from the wells, the drainage performance of this aquifer (IWDI) increases significantly up to $84 \%$ of drainage index against $16 \%$ of other mechanisms that contribute to oil drainage in the Upper Pinda reservoir. This water drainage mechanism in the Upper Pinda reservoir of the Mibale field caused a modification of water oil contact from 5720 to 5500 feet towards the top of the structure, which represents 220 feet during the 42 years of operation due 5. 23 feet per year. This allows us to categorize this aquifer as: linear and semi-radial. The graph of Alvena and Odeh shows that the Stock Tank Original Oil In place $(\mathrm{N})$ is currently 4.5 million barrels with recovery factor $31 \%$. This inactive aquifer is located in the carbonate Karst of Upper Pinda, to the north of the deposit. Being inactive, this aquifer is not at the origin of breakthrough or coning water acting in this field. It is likely that this phenomenon is amplified by water flooding. which allows us to classify water flooding technology among aquifer drainage mechanisms; since this significantly activates the behavior of the aquifer and has the same effects as the aquifer.

\section{Nomenclature}

\footnotetext{
$\mathrm{r}_{\mathrm{e}}$ External boundary radius

$\mathrm{r}_{\mathrm{D}}$ dimensionless radius $=\frac{r}{r_{w}}$

$\mathrm{r}_{\mathrm{eD}}$ dimensionless radius $=\frac{r_{w}}{r_{w}}=\frac{r_{e}}{r_{o}}$

$\mathrm{r}_{\mathrm{o}}$ reservoir radius

$\mathrm{r}_{\mathrm{w}}$ wellbore radius

$\mathrm{R}_{\mathrm{p}}$ cumulative gas oil ratio

$\mathrm{R}_{\mathrm{s}}$ solution or dissolved gas oil ratio

$\mathrm{W}_{\mathrm{e}}$ cumulative water influx

$\mathrm{W}_{\mathrm{D}}$ dimensionless cumulative water influx

$\mathrm{U}$ aquifer constant

$\mathrm{T}_{\mathrm{D}}$ dimensionless time

$\mathrm{N}$ stock tank oil initially in place (STOIIP)
}

$\phi$ porosity

$\mu$ viscosity

$\bar{c}$ total aquifer compressibility $\left(\mathrm{C}_{\mathrm{w}}+\mathrm{C}_{\mathrm{f}}\right)$

$C$ constant dependent of the time

$m$ gas cap factor

$\Delta \mathrm{P}$ pressure drop

G: Volume Initially of Gas in deposit

MSCF: Million Standard Cubic Feet

MIOC: Moanda International Oil Company

OWC: Oil Water Contact 


\section{Funding}

This research has not received any specific grant from funding organizations in the public, commercial or non-profit sectors.

\section{Acknowledgements}

We would like to thank the Operating company PERENCO REP DRC and Muanda International Oil Company for providing the data used in this study. We also recognize Dr LUBANZADIO MAVATIKUA to London for his remarks, advice and inputs during the final stage of this paper manuscript.

\section{References}

[1] Abhijit Y. Dandekar, 2013: Petroleum Reservoir Rock and Fluid properties.

[2] Bimbanga-Kumbana Wa Baki, 1991: Suivi de la production et de l'injection d'eau sur le champ MIBALE dans la concession ZAGOC.

[3] B. C. Craft, M. Hawkins, 1990: Applied Petroleum Reservoir Engineering 2th edition 226p.

[4] Gaffney, Cline \& Associates, 1987: A study of reserves of the coastal basin, republic of zaire. Mibale field review.

[5] Gaffney and al, 1988: Étude sur les réserves du bassin littoral de la république du zaïre. Compte rendu du gisement de MIBALE Est/TSHIENDE.

[6] Gia Luigi Chierici, 1994: Principles of Petroleum Reservoir Engineering. 421p Springer International Publishing.

[7] John R. Fanchi, 2006: Principales of Applied Reservoir Simulation, 3th Edition Gulf Professional Publishing, Elsevier $517 \mathrm{p}$.

[8] John R. and al, 2017: Introduction to Petroleum Engineering. $344 p$.
[9] J. R. Ursin and A. B. Zolotukhin Stavanger, 1997: Fundamentals of Petroleum Reservoir Engineering. 217p.

[10] L. P Dake, 1978: Fundamentals of reservoir engineering, Elsevier scientific publishing company. Book.

[11] L. P Dake, 2001: The practice of Reservoir Engineering Revised edition.

[12] Logar J. F, 1989: Well Evaluation conference-Wouest Africa, Edition Schlumberger, Paris.

[13] Ma Y. Zee, 2019: Quantitative Geosciences data analysics, Geostatistics, Reservoir characterization and Modelling. 640p Springer International Publishing.

[14] M. J. Fetkovich, spe aime, phillips petroleum co, 1971: A Simplified Approach to Water Influx Calculations-Finite Aquifer Systems Published in Journal of Petroleum Technology.

[15] Nnaemaka Ezekwe, 2011: Petroleum Reservoir Engineering Practice, 801p.

[16] Ronald e. Terry, j. brandon rogers, 2015: Applied petroleum Reservoir Engineering $3^{\text {th }}$ Edition.

[17] Oloro John, Ukrakpor Erhimudia Friday, 2011: Determination of water influx in reservoir in niger delta Published in Wilolud Journals.

[18] Okotie and al, 2019: Reservoir Engineering, Fundamentals and applications. 416p Springer International Publishing.

[19] Saleh G. and al, 2020: Aquifer characterization and Modelling, a case study of Oil Field. University Bullettin- ISSUE $\mathrm{N}^{\circ} 2-$ Vol (1)-2020.

[20] Tavakoli, Vahid, 2020: Carbonate Reservoir Heterogeneity, Overcoming the challenges. 108p.

[21] Tarek Ahmed, 2001: Reservoir engineering hand book, $2^{\text {th }}$ Edition, Gulf Professional Publishing, 1211p.

[22] Tarek Ahmed, 2010: Reservoir Engineering handbook, 4th Edition, Gulf Professional Publishing, 1463p.

[23] William E. Brigham, 1997: Water Influx and Its effect on Oil Recovery; First Part, Aquifer Flow 109p. 